\section{InI)ret}

3.2020

Miguel Ángel Boldova Pasamar

Universidad de Zaragoza

\title{
El actual entendimiento de los delitos de violencia de género y sus perspectivas de expansión
}

\begin{abstract}
Sumario
Los delitos contra la violencia de género de carácter ocasional, que se introdujeron a finales de 2004 en la legislación penal española para combatir de un modo especialmente intenso las violencias físicas y psicológicas del hombre sobre su pareja o expareja femenina, no solo superaron el filtro de constitucionalidad, sino que en la actualidad de aplican de forma automática y objetivista. No resulta preciso probar para la imposición de una pena superior ni motivaciones discriminatorias del autor, ni relaciones de poder o dominio sobre la víctima. Siguiendo las prescripciones del Convenio de Estambul, nuestro legislador parece dispuesto a ampliar el elenco de figuras delictivas en las que está o puede estar presente el componente de género, al pretender incluir dentro del catálogo de delitos de esta naturaleza otras violencias contra la mujer, particularmente las sexuales, más allá del limitado ámbito de la pareja.
\end{abstract}

\begin{abstract}
In 2004 Spain changed the criminal legislation to include gender motivated offenses, in order to severely fight more against the physical and psychological violence perpetrated by men against their present or former female partners. The new legislation not only passed the constitutionality control but has also being applied automatically and in an objective way. Therefore, it is not mandatory to prove neither discriminatory motivations of the perpetrator nor power relations or dominance over the victim for the imposition of a higher penalty. Following the prescriptions of the Istanbul Convention, the Spanish legislator seems willing to expand the list of offenses in which the gender component is or may be present, aspiring to include other forms of violence against women beyond the limited scope of the couple, particularly in cases of sexual violence.
\end{abstract}

\begin{abstract}
Die Straftaten gegen geschlechtsspezifische Gewalt gelegentlicher Art, die Ende 2004 in das spanische Strafgesetzbuch eingeführt wurden, um die physische und psychische Gewalt von Männern gegen ihre jetzigen oder ehemaligen Partnerinnen besonders intensiv zu bekämpfen, haben nicht nur die Kontrolle der Verfassungsmäßigkeit bestanden, aber sie werden derzeit automatisch und objektiv angewandt. Daher ist es nicht erforderlich, für die Auferlegung einer höheren Strafe weder diskriminierenden Motivation des Täters noch Machtverhältnisse oder Dominanz über das Opfer nachzuweisen. Nach den Vorschriften des Übereinkommens von Istanbul scheint der spanische Gesetzgeber bereit zu sein, die Zahl der Straftaten, in denen die geschlechtsspezifische Komponente vorkommt oder vorhanden sein könnte, zu erweitern. Er beabsichtigt daher, andere Gewalttaten gegen Frauen, insbesondere sexuelle, in den Katalog solcher Straftaten, über den begrenzten Umfang des Paares hinaus aufzunehmen.
\end{abstract}

Title: The current understanding of gender violence crimes and their expansion perspectives

Titel: Das derzeitige Verständnis von Verbrechen gegen geschlechtsspezifische Gewalt und ihre Expansionsperspektiven 
Palabras clave: violencia de género, violencia contra la mujer, violencia sexual, igualdad y no discriminación

Keywords: violence of gender, violence against women, sexual violence, equality and nondiscrimination

Stichwörter: geschlechtsspezifische/geschlechtsbezogene Gewalt, Gewalt gegen Frauen, sexuelle Gewalt, Gleichstellung und Nichtdiskriminierung

DOI: $10.31009 / \mathrm{InDret} .2020 . \mathrm{i3} .06$ 


\section{InI)ret}

3.2020

Recepción

27/01/2020

Aceptación

$12 / 05 / 2020$
Índice

1. Introducción

2. La interpretación literal y objetiva de los delitos de violencia de género ocasional

3. La irrupción de la agravante de género

4. Los trabajos preliminares para alcanzar un Pacto de Estado en materia de violencia de género: aspectos de Derecho Penal sustantivo

5. El Pacto de Estado en materia de violencia de género (texto refundido de 13 de mayo de 2019): las propuestas penales de reforma

6. Epílogo

7. Bibliografía

Este trabajo se publica con una licencia Creative Commons Reconocimiento-No Comercial 4.0 Internacional (c) (1) (9) 


\section{Introducción*}

Han trascurrido más de quince años de vigencia de la Ley Orgánica de medidas de protección integral contra la violencia de género (LO 1/2004, de 28 de diciembre). Una ley que gozó de la unanimidad de la clase política para su aprobación, aunque las medidas de carácter penal fueron de las más discutidas al implantar por primera vez en el Derecho Penal español una discriminación o asimetría penológica por géneros con relación a determinados tipos penales. ${ }^{1}$ No obstante, esa misma unanimidad se ha plasmado recientemente en el "Pacto de Estado contra la violencia de género", que busca ampliar los recursos de carácter jurídico-penal frente ese estigma social, en contra de la opinión generalizada de la doctrina penal, a la que se ha ignorado por completo.

Una parte de aquellas medidas de la LO 1/2004 consistió en insertar en el Código penal una serie de tipos delictivos contra la integridad física y la libertad, que se agruparon bajo el común denominador de una clase determinada de "violencia de género" -la producida por el varón contra la mujer en el ámbito de la pareja-, y que consagraron la diferenciación penológica según que fuera el hombre o la mujer quien realizara externamente el mismo comportamiento. La comprensión jurisprudencial de las normas subyacentes a estos delitos ha evolucionado a lo largo de los años y en la actualidad puede decirse que ha culminado una determinada interpretación de los preceptos penales que, si bien es cierto no es unánime, mayoritariamente y en la práctica prescinde del plano subjetivo y personal en el que se realiza el delito para concentrarse solo en el objetivo y comunitario al objeto de afirmar la concurrencia del correspondiente delito de género, incurriendo en un automatismo total $\mathrm{y}$, por ello, preocupante.

Entre tanto el legislador de 2015 amplió el catálogo de delitos más directamente relacionados con la violencia contra la mujer, algunos de ellos derivados de los compromisos internacionales contenidos principalmente en el Convenio del Consejo de Europa sobre prevención y lucha contra la violencia contra la mujer y la violencia doméstica (hecho en Estambul el 11 de mayo de 2011), en la Directiva 2011/36/UE (del Parlamento Europeo y del Consejo, de 5 abril de 2011, relativa a la prevención y lucha contra la trata de seres humanos y a la protección de las víctimas), y en la Convención sobre la eliminación de todas las formas de discriminación contra la mujer de Naciones Unidas (Resolución 34/180, de 18 de diciembre de 1979). En su virtud se tipificaron expresamente en el CP los matrimonios forzados (art. $172 \mathrm{bis}$ ), el acoso persecutorio (art. 172 ter) y la divulgación no autorizada de imágenes o grabaciones íntimas obtenidas con la anuencia de la persona afectada (art. 197.7), aunque en estas figuras no se incluyeron las asimetrías penológicas de los delitos de violencia de género. Asimismo, incorporó dentro del catálogo de circunstancias agravantes generales o comunes la de cometer el delito por "razones de género", vinculada conceptualmente a las definiciones del citado Convenio de Estambul, aunque no a sus prescripciones.

\footnotetext{
"Autor de contacto: Miguel Ángel Boldova Pasamar, mboldova@unizar.es. Este trabajo se vincula con una de las líneas de investigación del Grupo de Estudios Penales, financiado por el Gobierno de Aragón y el Fondo Europeo de Desarrollo Regional (“Construyendo Europa desde Aragón”).

${ }^{1}$ Boldova Pasamar/Rueda MARTín, «Consideraciones político-criminales en torno a los delitos de violencia de género», en BOLDOVA PASAMAR/RUEDA MARTín (coord.), La reforma penal en torno a la violencia doméstica y de género, 2006, pp. $18 \mathrm{~s}$.
} 
Por último, en el marco de la revisión de la LO 1/2004 y con la pretensión de aumentar los recursos del Derecho Penal contra la violencia machista, el siguiente paso que se anuncia por parte del legislativo español, según manifiesta en el Pacto de Estado contra la violencia de género (en su versión de 13 de mayo de 2019, que contiene el documento refundido de medidas propuestas por el Congreso y por el Senado), ${ }^{2}$ consiste, entre otras medidas, en las siguientes: ampliar el concepto de violencia de género a todos los tipos de violencia contra las mujeres contenidos en el Convenio de Estambul, modificar o ampliar algunos delitos que aparecen como expresión de la denominada violencia de género, limitar las circunstancias atenuantes, así como extender el campo de aplicación de las circunstancias agravantes, y no solo la de género, sino también de circunstancias comunes (como la reincidencia).

En este trabajo se estudia la comprensión de los tipos de violencia de género del CP, así como del conjunto de delitos que aparecen también como manifestaciones diversas de la violencia contra la mujer por razones de género, a partir de la fundamentación teórica actualmente dominante dirigida a explicar la eventual mayor intensidad de la respuesta penal, bien sea mediante tipos cualificados, bien mediante circunstancias modificativas de la responsabilidad criminal, y los argumentos para mantener o rechazar la coherencia del sistema, así como su adecuación a los principios fundamentales del Derecho Penal.

\section{La interpretación literal y objetiva de los delitos de violencia de género ocasional}

Por lo que respecta a la visión actual de los delitos de violencia de género, hoy por hoy para la jurisprudencia española "toda" agresión de un hombre a una mujer, cuando exista o haya existido relación entre ellos, constituye violencia de género. La STS 677/2018, de 20 de diciembre (MP: Vicente Magro Servet), eliminó la posibilidad de soslayar la aplicación del art. $153 \mathrm{CP}$ a los supuestos de maltrato bidireccional o riñas mutuas en la pareja, uno de los pocos supuestos -prácticamente el único $-{ }^{3}$ que daban lugar a la exclusión excepcional del precepto indicado.

En realidad, a partir de esta sentencia ningún caso de maltrato de obra o de lesiones leves en ese ámbito puede quedar excluido en la práctica de la vis attractiva de los delitos de violencia de género. Así se consolida una interpretación objetiva y una aplicación literal y automática de los tipos de violencia de género relacional, pues no requiere prueba alguna sobre aspectos objetivos o subjetivos que pudieran estar dirigidos a abonar el carácter de "género" de la violencia correspondiente. Aunque en principio la STS mencionada se refiere al delito del art. 153.1 CP, su doctrina es extensible a los demás preceptos que recogen la relación típica entre

\footnotetext{
${ }^{2}$ Disponible en internet a través del portal de la Delegación del Gobierno para la Violencia de Género o, directamente:

http://www.violenciagenero.igualdad.mpr.gob.es/pactoEstado/docs/Documento Refundido PEVG 2.pdf

${ }^{3} \mathrm{Al}$ margen quedan los hechos en los que no se aprecia entidad y textualmente se descarta que estemos ante una manifestación de violencia de género, como: "discrepancias y reproches en relación con la conducta que adopta la madre para con los hijos comunes" (AAP de Cáceres, sec. 2, 913/2017, de 18 diciembre), o discusiones constantes y "lenguaje hasta soez y cuanto menos poco educado, estando presente el hijo común, de tres años, en varias de ellas” (AAP de Murcia, sec. 3, 792/2018, de 30 de noviembre). Igualmente, se estima atípico y excluido de la violencia de género el acto de colocar la mano en la boca de la esposa en el devenir de una discusión verbal (SAP de Badajoz, sec. 1, 59/2017, de 19 junio, "no constituye un delito de violencia de género, no integra un maltrato de obra. Otra interpretación es sencillamente inapropiada y desmesurada”, revocando la condena recaída en la primera instancia).
} 
un sujeto activo varón y un sujeto pasivo mujer que eran pareja en el momento de los hechos o lo fueron en un momento anterior. ${ }^{4}$

La incorporación al CP, merced a la LO 1/2004, de los tipos que castigan con una pena superior al hombre respecto de la mujer en las distintas manifestaciones de la violencia de género, como son lesiones, malos tratos, amenazas y coacciones (arts. 148.4. ${ }^{\circ}, 153.1,171.4$ y 172.2), aparentemente al margen de exigencias probatorias, ${ }^{5}$ dio lugar a un intenso debate sobre la constitucionalidad de la diferenciación penológica, y ello con base en una posible vulneración de los principios de igualdad y de culpabilidad, así como del derecho a la presunción de inocencia, ${ }^{6}$ que fue resuelta en su momento por el TC en varias sentencias desde su primer pronunciamiento en la STC 59/2008, de 14 de mayo (MP: Pascual Sala Sánchez), aunque con la existencia de relevantes y numerosos votos particulares, que ponían de relieve que la cuestión no quedaba completamente solventada, como así fue.

Según esta transcendental sentencia del TC: "El legislador no presume un mayor desvalor en la conducta descrita de los varones (...) a través de la presunción de algún rasgo que aumente la antijuridicidad de la conducta o la culpabilidad de su agente. Lo que hace el legislador, y lo justifica razonablemente, es apreciar el mayor desvalor y mayor gravedad propios de las conductas descritas en relación con la que tipifica el apartado siguiente. No se trata de una presunción normativa de lesividad, sino de la constatación razonable de tal lesividad a partir de las características de la conducta descrita y, entre ellas, la de su significado objetivo como reproducción de un arraigado modelo agresivo de conducta contra la mujer por parte del varón en el ámbito de la pareja. (...) el legislador aprecia una gravedad o un reproche peculiar en ciertas agresiones concretas que se producen en el seno de la pareja o entre quienes lo fueron, al entender el legislador, como fundamento de su intervención penal, que las mismas se insertan en ciertos parámetros de desigualdad tan arraigados como generadores de graves consecuencias, con lo que aumenta la inseguridad, la intimidación y el menosprecio que sufre la víctima".

Se trataba en el fondo, según se indicaba en sus votos particulares y en la doctrina penal que analizó dicha resolución (y que mayoritariamente optó por realizar una interpretación de los preceptos que los dotara de un fundamento material que impidiera el automatismo en su aplicación), ${ }^{7}$ de una sentencia interpretativa de la constitucionalidad de un precepto para orientarlo hacia una fundamentación de la asimetría penológica, no sobre la base de una diferencia biológica entre los sujetos activo y pasivo del delito ${ }^{8}$ sino en virtud de las pautas

\footnotetext{
${ }^{4}$ Tan solo el carácter potestativo del tipo cualificado del art. 148.4. ${ }^{\circ}$ podría suponer una excepción al indicado automatismo de la agravación.

5 SANZ MuLAS, «El primer paso fallido del Real Decreto-Ley 9/2018, de 3 de agosto, de medidas urgentes para el Pacto de Estado contra la violencia de género», $R P, 2019$, (43), p. 140, estima que la propia LO $1 / 2004$, al incluir en el CP estos delitos sin exigir el componente discriminatorio y sí solo el vínculo afectivo, aboga por la aplicación automática de los tipos delictivos.

${ }^{6}$ Independientemente de otros motivos de inconstitucionalidad que se apuntan, como el derivado de una jurisdicción especial denominada de violencia contra la mujer, que podría hacer dudar de la igualdad de las partes en el proceso; vid. TAMARIT SUMALLA, «Violencia de género: una política criminal sin base empírica», El cronista del Estado Democrático y Social de Derecho, (77), 2018, pp. 24 s.

${ }^{7}$ Vid. en este sentido ALASTUEy DoBÓN/ESCUCHURI AISA, «La violencia de género y la violencia doméstica en el contexto legislativo español», RDP, (23), 2015, p. 51.

${ }^{8}$ Vid. ACALE SÁNCHEZ, "Análisis del Código penal en materia de violencia de género contra las mujeres desde una perspectiva transversal», REDUR, (7), 2009, pp. 39 s., quien alude a que el TC habría declarado inconstitucional una determinada lectura del art. 153.1, y precisamente la que fundamenta las diferencias penológicas en la distinta biología de los sujetos activo y pasivo del delito. Contrarias al carácter interpretativo de la STC 59/2008: GARCÍA ARÁN, «Injusto individual e injusto social en la violencia
} 
culturales -de género- que son inherentes o consustanciales al maltrato en la pareja por parte del hombre a la mujer de quien es o ha sido pareja y que dotan a la conducta de un plus de lesividad. ${ }^{9}$

Aunque aparentemente la interpretación constitucional de los tipos de violencia de género habría zanjado toda discusión sobre la aplicabilidad de los delitos correspondientes, ${ }^{10}$ en realidad no quedó definitivamente resuelta la cuestión de si debía ser objeto de prueba en el proceso penal la concurrencia de un elemento objetivo, de uno subjetivo o de ambos, en todo caso relacionados con el carácter de género que acompaña a esa clase de violencia relacional. El elemento objetivo se circunscribiría a la existencia de una situación de desequilibrio entre los sujetos o a una posición de dominio del hombre sobre la mujer. El subjetivo haría referencia a la existencia de motivación o ánimo discriminatorio, machista o sexista del autor del delito. Estos elementos se tomarían en consideración en casos minoritarios, aquellos más problemáticos o discutibles y porque lo alega la parte acusada, confirmando con esta excepción la regla general contenida en la ley penal relativa a la mayor gravedad de la violencia en la pareja que fuera de ella, y particularmente la de género sobre cualquier otra.

En efecto, la aplicación de los tipos de violencia de género no ha planteado un problema en la práctica cuando ha sido de carácter unidireccional, esto es, el supuesto más frecuente (agresiones, amenazas y coacciones del hombre contra su pareja femenina), puesto que en principio ha bastado la constatación de la previa existencia de una relación presente o pasada de pareja y que la conducta agresiva hubiera sido realizada por un hombre contra una mujer, sin entrar a considerar elementos de desequilibrio, dominación, discriminación o machismo, ${ }^{11}$

machista. (A propósito de la STC 59/2008 sobre el maltrato masculino a la mujer pareja)», en CARBONELL MATEU et al. (coords.), Constitución, derechos fundamentales y sistema penal. Semblanzas y estudios con motivo del setenta aniversario del Profesor Tomás Salvador Vives Antón, t. I, 2009, p. 658; ROIG TORRES, «La delimitación de la "violencia de género": un concepto espinoso», Estudios Penales y Criminológicos, (32), 2012, p. 299.

${ }^{9} \mathrm{~A}$ este respecto se ha dicho que el fundamento material para explicar las agravaciones de género radica en que la condición de mujer, en virtud de la radical desigualdad en el reparto de roles sociales, es un factor específico que incrementa el riesgo de ser víctima de actos de violencia a manos de su pareja masculina; en este sentido LAURENZO COPELLO, «La violencia de género en la Ley Integral. Valoración político-criminal», RECPC, (7-8), 2005, pp. 17 ss. Desde este punto de vista, en toda agresión del varón a su pareja femenina estaría presente ese mayor riesgo o esa mayor lesividad (así también MAQUEDA ABREU, «La violencia contra las mujeres: una revisión crítica de la Ley Integral», $R P$, (18), 2006, p. 179). En cambio, en términos menos absolutos, para LARRAURI PIJOAN, «Igualdad y violencia de género. Comentario a la STC 59/2008», InDret, (1), 2009, p. 11, en general el acto del hombre hacia su pareja femenina es más grave, y ello se debe a dos motivos: el mayor temor que la agresión de un hombre ocasiona y la mayor posibilidad de que se produzca un resultado lesivo. Añade también que en general la mujer en pareja está en situación de mayor vulnerabilidad producto precisa y adicionalmente de su vida en pareja.

${ }^{10}$ Atribuida también, singular y decisivamente, a la “operación de cirugía estética” que sufrió la LO 1/2004 en fase de proyecto con la inclusión del segundo grupo de personas especialmente protegidas, esto es, las especialmente vulnerables que convivan con el autor. Puesto que de esa manera se igualaba en cierta medida la asimetría entre géneros y se permitía soslayar la tacha por violación del principio de igualdad y del derecho a no ser discriminado, al poder resultar también víctima del tipo cualificado el hombre especialmente vulnerable- agredido por su pareja femenina; vid. en este sentido ACALE SÁNCHEZ, «Derecho Penal y violencia de género», en MARTín SÁNCHEZ (dir.), Estudio Integral de la Violencia de Género: un análisis teórico-práctico desde el Derecho y las Ciencias Sociales, 2018, pp. 410, 414.

${ }^{11}$ En el Estudio sobre la aplicación de la Ley integral contra la violencia de género por las Audiencias Provinciales (realizado por el CGPJ, publicado en marzo de 2016 y accesible desde la web del Poder Judicial: www.poderjudicial.es), se indica que "la mayor parte de las resoluciones de las Audiencias Provinciales analizadas no abordan este tema, lo que significa que la cuestión relativa a la integración o no del referido elemento finalístico en los delitos de violencia de género no ha sido, en estos casos, 
pero máxime si se ponían de manifiesto (STS 58/2008, de 25 de enero). Cabe destacar que muchas de esas causas acaban en sentencias de conformidad, por lo que, admitida la culpabilidad, nada más hay que investigar. ${ }^{12}$

No obstante, la regla general de que la violencia del hombre contra su pareja femenina constituye un delito de violencia de género ha contado con excepciones, puesto que en algunas ocasiones y concretamente en las hipótesis de agresiones mutuas o de violencia bidireccional a veces se ha hecho depender la apreciación del delito correspondiente de género de la prueba de la concurrencia, o bien de una situación objetiva de desequilibrio o de una posición de dominio del hombre, o bien de un elemento subjetivo concretado en un ánimo discriminatorio. ${ }^{13}$ Dicha exigencia se había fundamentado en la finalidad u objeto de la LO 1/2004 puesta de manifiesto y declarada en su art. 1.1: "La presente Ley tiene por objeto actuar contra la violencia que, como manifestación de la discriminación, la situación de desigualdad y las relaciones de poder de los hombres sobre las mujeres, se ejerce sobre éstas por parte de quienes sean o hayan sido sus cónyuges o de quienes estén o hayan estado ligados a ellas por relaciones similares de afectividad, aun sin convivencia". Pues bien, el mutuo acometimiento en igualdad de condiciones y con resultados similares sería una señal de que no se produce la situación de desigualdad o de desequilibrio que son el contexto propio de las denominadas conductas "machistas".

La tendencia en esa jurisprudencia que apreciaba un elemento adicional en las hipótesis de agresiones mutuas o que, mejor dicho, descartaba los tipos de violencia de género si en el caso concreto no se ponía de manifiesto una situación de vulnerabilidad, de superioridad, de discriminación, etc., reconduciendo los hechos a la respectiva falta, se mantuvo tras los pronunciamientos del TC sobre la correspondencia de los tipos de violencia de género con la Constitución. ${ }^{14}$ Dicha jurisprudencia, en principio menor, la hizo suya el propio TS (a partir de la STS 654/2009, de 8 de junio), que de alguna manera enmendaba la plana al TC, haciendo una

suscitada por las partes. Cuando sí ha sido objeto de debate o cuando las Audiencias Provinciales han examinado esta cuestión de oficio, lo que ha sucedido en un 13,24\% de las sentencias que constituyen la muestra de estudio, en un 60,35\% de supuestos se han decantado por entender que el artículo 1 de la Ley Integral define un elemento subjetivo en los delitos de violencia de género" (pp. $210 \mathrm{~s}$.).

${ }^{12}$ Según el Boletín n. ${ }^{\circ} 43$ del CGPJ, en el periodo que va del segundo semestre de 2005 al primero de 2015 , en los Juzgados de violencia contra la mujer, de las 192.804 sentencias dictadas por estos órganos, 148.894 han sido condenatorias, de ellas 107.264 han correspondido a sentencias de conformidad del acusado y el resto, 41.630, a condenas en juicio de faltas. A tenor del Informe trimestral sobre violencia de género del Observatorio contra la violencia doméstica y de género del CGPJ correspondiente al año 2018, las condenas de conformidad en los Juzgados de lo Penal en procesos de violencia de género, representaron el $30,5 \%$ de las formas de terminación posibles, frente al $24,4 \%$ de sentencias condenatorias sin conformidad.

${ }^{13}$ Vid., por ejemplo, SAP de Barcelona (sec. 20) 620/2006, de 19 julio y 950/2007, de 31 octubre (la pelea mutua declarada probada implica la igualdad de condiciones, las agresiones mutuas y la adopción por ambos de un posicionamiento activo en la pelea que nada tiene que ver con actos realizados por el hombre en el marco de una situación de dominio discriminatoria para la mujer); SAP de Valencia (sec. 1) $437 / 2008$, de 27 noviembre y 451/2008, de 3 de diciembre (en supuestos como el presente en el que el maltrato del hombre sobre la mujer es recíproco y simultaneo con el maltrato de la misma sobre el hombre, normalmente producido cuando tiene lugar una pelea en la que los dos contendientes aceptan el daño propio y del otro, actuando movidos por la intención de vencer al oponente en situación pareja, no se puede calificar el suceso como una manifestación de dominio del hombre sobre la mujer o como un estado de vulnerabilidad de ésta, ni tampoco se puede atribuir al acusado varón la prueba de que su acción dolosa comprende la conciencia de tal superioridad o de que se mueve impelido por dicho convencimiento).

${ }^{14}$ SAP de Castellón 253/2011 (sec. 2), de 30 mayo (con cita de numerosas sentencias de Audiencias Provinciales). 
relectura constitucional del precepto para las hipótesis de violencia bidireccional en la pareja: "no toda acción de violencia física en el seno de la pareja del que resulte lesión leve para la mujer, debe considerarse necesaria y automáticamente como la violencia de género que castiga el nuevo art. 153 C.P. (...), sino sólo y exclusivamente -y ello por imperativo legal establecido en el art. 1.1 de esa Ley- cuando el hecho sea "manifestación de la discriminación, de la situación de desigualdad y de las relaciones de poder del hombre sobre la mujer". (...) Pues bien, todo lo expuesto avala la necesidad de que el acusado pueda defenderse de la imputación, proponiendo prueba en el ejercicio de su derecho constitucional a la tutela judicial efectiva a fin de acreditar las circunstancias concurrentes al realizar la conducta típica, así como el "animus" que impulsaba la acción (...)" (STS $1177 / 2009$, de 24 noviembre).

En todo caso también evolucionó la jurisprudencia del TS cuestionando la necesidad de constatar un elemento subjetivo y circunscribiendo la prueba única y exclusivamente al elemento contextual objetivo. ${ }^{15}$ Así, se indica tanto en el ATS 31-07-2013 (n. ${ }^{\circ}$ rec. 20663/2012) como en la STS 856/2014, de 26 diciembre: "Es verdad que de acuerdo con la jurisprudencia constitucional para la aplicación del art. 153.1 CP se exige un sustrato que ponga de manifiesto que la agresión, se enmarca en el contexto de una reprobable concepción implantada en ámbitos culturales o sociales de predominio del varón sobre la mujer. Pero eso no significa que sea necesario un elemento subjetivo peculiar o un dolo específico. La presunción juega en sentido contrario. Sólo si consta o hay evidencias de que el episodio, concreto o reiterado, de violencia es totalmente ajeno a esa concepción que ha estado socialmente arraigada, y que la agresión o lesión obedece a unas coordenadas radicalmente diferentes, no habría base para la diferenciación penológica y habrá que castigar la conducta a través de los tipos subsidiarios en que la condición de mujer del sujeto pasivo no representa un título de agravación penológica. Pero en principio una agresión en ese marco contextual per se y sin necesidad de prueba especial está vinculada con la concepción que el legislador penal se propone erradicar o al menos reprobar".

Realmente lo que late es la idea de que la pura literalidad de la redacción de los preceptos de violencia de género cuestionados sería inconstitucional si no fuera corregida por vía interpretativa. De ahí que considere el TS en la sentencia y auto arriba indicados que la STC 59/2008 "desde luego, contiene alguna dosis de ambigüedad, criticada por alguno de sus numerosos votos particulares, por no haber extraído de manera explícita la conclusión que sí es sugerida. Pero en general se puede estar conforme en entender que a raíz de tal pronunciamiento no serán sancionables por la vía del art. $153.1^{\circ}$ episodios desvinculados de esas pautas culturales de desigualdad que se quieren combatir (por buscar un ejemplo claro e indiscutible: agresión recíproca por motivos laborales de dos compañeros de trabajo que estuvieron casados mucho tiempo antes)". De modo que la ratio de la constitucionalidad del precepto, interpretado a la luz de su finalidad, implicaría introducir en el tipo lo que la letra de la ley no dice, pero sí la sentencia del TC, por lo que, según el TS (invocando un voto particular de aquella sentencia del TC): "para que una conducta sea subsumible en el art. 153.1 del Código Penal no basta con que se ajuste cumplidamente a la detallada descripción que contiene, sino que es preciso además que el desarrollo

\footnotetext{
${ }^{15}$ Esta alternativa al elemento subjetivo para la interpretación, aplicación o explicación del fundamento de los tipos de violencia de género también se encuentra avalada por un sector de la doctrina; v, por ejemplo: LAURENZO COPELLO, «¿Hacen falta figuras de género específicas para proteger a las mujeres?», Estudios Penales y Criminológicos, (35), 2015, pp. 819 ss.; PÉREZ MANZANo, «Algunas claves del tratamiento penal de la violencia de género: acción y reacción», RJUAM, (34), 2016, p. 42; LARRAURI PIJOAN, Criminología crítica y violencia de género, $2^{\mathrm{a}}$ ed., 2018, p. 133.
} 
de los hechos constituya "manifestación de la discriminación, situación de desigualdad y las relaciones de poder de los hombres sobre las mujeres”.

Al parecer pesaban más los votos particulares de las sentencias del TC que sus sentencias mayoritarias, aunque en éstas se señala más que clarísimamente que la previsión normativa de los tipos de violencia de género "no se sustenta en la existencia de una presunción legislativa de que en las agresiones del hombre hacia quien es o ha sido su mujer o su pareja femenina afectiva concurre una manifestación de discriminación, sino que (...) lo que hace el legislador, y lo justifica razonablemente, es apreciar el mayor desvalor y mayor gravedad propios de las conductas descritas" (SsTC 59/2008, 45/2009, 151/2009, 165/2009, 179/2009 y 41/2010), y ello tanto si la violencia es unidireccional como bidireccional (STC 69/2008, de 24 de julio). ${ }^{16}$

Es el propio TS el que, a raíz de la sentencia 677/2018, corrige su propia jurisprudencia y la hace coincidir definitivamente con la del TC, y no con la de sus votos particulares.

Tras lo señalado en aquélla no solo no hay necesidad de probar el ánimo de dominación o machismo del autor, sino que tampoco es preciso apreciar en el supuesto concreto su conexión con los denostados cánones de asimetría o con las pautas socioculturales del patriarcado. El acto de maltrato o violencia da cuenta por sí solo de su gravedad al producirse en el contexto de la pareja. Coincidiendo con lo afirmado en su momento por la Circular 4/2005, de 18 de julio, de la FGE, la STS 677/2018 reitera el entendimiento de que "los actos de violencia que ejerce el hombre sobre la mujer con ocasión de una relación afectiva constituyen actos de poder y superioridad frente a ella con independencia de cuál sea la motivación o la intencionalidad (...)”, a lo que añade que la existencia de una riña en la pareja no permite degradar la tipicidad, ni puede suponer un beneficio penal. Es decir, no se puede degradar a delito leve por vía interpretativa aquello que el legislador de 2003 quiso excluir del ámbito de las faltas, pues de otro modo, si no se denuncian mutuamente quienes se han agredido entre sí, como se indica en la referida sentencia, "no existiría procedimiento penal y no podrían sancionarse penalmente hechos para los que el legislador sí ha previsto específicamente una sanción por una tipicidad clara y concreta: para el hombre en estos casos el tipo descrito en el art. $153.1 \mathrm{CP}$, y para la mujer en el art. 153.2 CP".

En suma, lo relevante a los efectos de afirmar el delito para el TS es el "trasfondo sociológico del hecho", el cual determinaría la "objetividad del acto". Por tanto y en este aspecto la mayor gravedad del hecho pudiera parecer que responde a una responsabilidad objetiva por el acto, pues se produce al margen de intenciones y de contextos objetivos relativos a la pareja en concreto. ${ }^{17}$

\footnotetext{
${ }^{16}$ En dicha sentencia se narraba el caso de sendas denuncias interpuestas por dos esposos que, en el curso de una discusión en el domicilio familiar, se agredieron mutuamente, lanzando la acusada un cenicero de cristal a su esposo, que le causó una herida en el antebrazo izquierdo, y empujando el acusado a su esposa contra el sofá, agarrándola del brazo y tirándole del pelo, lo que le provocó una tumefacción y cervicalgia mecánica.

${ }^{17}$ Vid. ACALE SÁNCHEZ, «La perspectiva de género en el Derecho Penal Español», en Faraldo CABANA (dir.), Género y sistema penal: una perspectiva internacional, 2010, p. 26, la cual había mantenido ya hace tiempo que se trataba de "un supuesto de responsabilidad puramente objetiva", afirmando posteriormente que ello se había producido en un contexto de desconfianza del legislador hacia la labor judicial, a la que ha pretendido limitar al máximo mediante la incorporación de presunciones iuris et de iure de peligrosidad, de modo que la constatación del peligro es automática; vid. ACALE SÁNCHEZ, «La interpretación judicial del derecho penal desde la perspectiva holística del género», Jueces para la Democracia, (92), 2018, pp. 26 s.
} 
Si se considera que aquélla constituye una responsabilidad de carácter objetivo y absoluto, sin excepción ni prueba en contrario, se está dando la impresión de que se parte de presunciones legales irrebatibles sobre la correspondencia del hecho concreto con una pauta cultural o un modelo agresivo masculino. De algún modo la STS 677/2018 trata de esquivar la objeción afirmando que "no existe una presunción de dominación iuris et de iure, pero ello no es un elemento del tipo penal del art. 153", y esto se enlaza con el reconocimiento de una excepción, al margen de la agresión mutua, que residiría en que el acusado pudiera probar que en la comisión del hecho no concurre elemento intencional alguno constitutivo de violencia de género (invocando la STC de 22 de julio de 2010) ${ }^{18}$ o que el acto de dominación no existe. Pero añade que ello no se puede desvirtuar por la circunstancia de una agresión recíproca. Por tanto, estos casos quedan fuera de la excepción posible.

¿Significa esto que todavía existirían supuestos excepcionales al margen de la violencia de género, que no fueran los de violencias mutuas? ¿Se vuelve de este modo a la casilla de salida o es mera retórica? Pues se decía que no hay que probar voluntades o intenciones, ni tampoco contextos objetivos de dominación, pero se termina admitiendo que el acto de dominación puede no existir y que queda a cargo del acusado acreditarlo para excluir el delito.

Es decir, si se puede probar que no concurre un elemento intencional o un elemento relativo a la dominación y esta prueba daría lugar a la exclusión del acto de maltrato del 153.1, entonces, y como dice el voto particular de la STS 677/2018, se estaría admitiendo implícitamente que el elemento (intencional o el) de dominación es un elemento típico necesario presumido legalmente, frente al que cabe prueba en contrario. ${ }^{19}$ De otro modo no se entiende racionalmente qué elemento del delito se excluye con dicha prueba a cargo del acusado.

Si en las agresiones mutuas en pie de igualdad y con idénticos resultados no se puede entender excluido un acto de dominación -al contrario, debe afirmarse contrafácticamente que reproduce una pauta de dominación machista-, hay que preguntarse cuándo o bajo qué circunstancias se puede considerar ausente el acto de dominación, constituyendo una excepción a la aplicación del art. 153.1 CP.

Cabe destacar que esa supuesta excepción no sería posible alegarla en casos de amenazas y agresiones, sino únicamente -dice la STS 677/2018- en "supuestos muy concretos, como el conflicto producido entre ex parejas de hace tiempo, o hechos de coaccionar por motivos económicos motivado por la ruptura de la pareja, etc.”. Podemos pensar, por ejemplo, en algún caso de vis in rebus propia de las coacciones, como cambiar una cerradura con motivo de la ruptura de la pareja y de la convivencia del domicilio propio y exclusivo (incluso careciendo de motivación

\footnotetext{
${ }^{18}$ Dicha sentencia es citada por el TS sin que la misma (STC 41/2010) realmente señale el aspecto destacado en el texto que el TS le atribuye, sino que constituye la lectura o interpretación que hace el ponente de la STS 677/2018 de aquella sentencia. Esta cita trae su origen en la SAP de Alicante (sec. 1) 782/2010, de 29 de noviembre, de la que fue ponente también Vicente Magro Servet y después de ella otras tantas de la misma Audiencia y ponente que reproducen la cita a dicha STC (SsAP de Alicante, sec. 1, 231/2011, 256/2011, 564/2011, 143/2012, 518/2012, 819/2012, 264/2013, 387/2013, 645/2013, 20/2014, 664/2014, 665/2014, 104/2016, 193/2016 y 390/2016). También se recoge literalmente en el documento accesible desde la web del Poder Judicial, titulado «La carga de la prueba de la intención de dominación o machismo en la violencia de género», del mismo autor (vid. también en La ley penal, n. ${ }^{\circ}$ 104, 2013, p. 11).

${ }^{19}$ La cual, si se articula, daría lugar de acuerdo con este voto particular a la aplicación a ambos sujetos (hombre y mujer) del delito del art. $153.2 \mathrm{CP}$, y no al delito leve correspondiente del art. 147.2 ó 3, como hasta entonces venía entendiéndose por la jurisprudencia que inapreciaba el art. 153 en hipótesis de violencia bidireccional.
} 
económica), pero no cabe imaginar otros supuestos de vis física o moral en los que pudiera tomarse en consideración el hecho como uno ajeno a la violencia de género (en particular si se recurre a la violencia o a la amenaza de violencia), pues, como señala la STS 807/2010, de 30 de septiembre, "es por completo indiferente que la motivación hubiera sido económica o de otro tipo, cuando lo cierto es que el acusado hizo uso de la fuerza física para imponer una conducta contra su voluntad a la perjudicada". Y en la misma STS 677/2018 se indica que "el empleo de la violencia y la relación de convivencia colman las exigencias del tipo, con independencia de la motivación que anima al autor" o, si hablamos en términos objetivos, de la existencia de un contexto objetivo de desequilibrio o de dominación que tampoco sería necesario probar. Por ello no parece tan claro e indiscutible el ejemplo con que ilustraba en esos términos la STS 856/2014, de 26 diciembre, la inaplicabilidad del art. 153, esto es, agresión recíproca por motivos laborales de dos compañeros de trabajo que estuvieron casados mucho tiempo antes, en tanto concurra una agresión, es decir, un acto propio de violencia.

En mi opinión, si se parte de que la gravedad de un acto de maltrato masculino es siempre objetivamente superior que la que corresponde al acto que se produce fuera del ámbito relacional de la pareja, carece de sentido permitir excepción alguna y menos una basada en la ausencia de un determinado elemento subjetivo del autor, aunque tampoco la derivada de un contexto objetivo de dominación en el caso concreto, puesto que la mayor gravedad del comportamiento no se deduce de consideraciones personales de los individuos en conflicto, sino de un trasfondo colectivo o sociológico que va más allá. Es decir que, por encima de los bienes jurídicos individuales, se alzan otros de naturaleza colectiva que influyen en la consideración de los hechos y del delito como una manifestación de la violencia de género. ${ }^{20}$

Sin embargo, el mensaje que se deriva de esta concepción colectivizada de las violencias de género, ${ }^{21}$ no favorece una función pedagógica de los preceptos legales si realmente resulta

\footnotetext{
${ }^{20}$ Vid. Acale SÁnchez, en FaRALdo Cabana (dir.), Género y sistema penal: una perspectiva internacional, 2010, pp. 25 ss., y LA MiSMA, en MARTÍN SÁNCHEZ (dir.), Estudio Integral de la Violencia de Género: un análisis teórico-práctico desde el Derecho y las Ciencias Sociales, 2018, pp. 418 s., quien apunta a un bien jurídico colectivo, delimitado en el contexto social e histórico de la violencia que sufren las mujeres en las relaciones de pareja, consistente en "la pertenencia de la víctima al género femenino históricamente subyugado por el género masculino"; aunque de ese modo, para la citada autora, estaríamos ante un supuesto de responsabilidad puramente objetiva construido sobre la base de presunciones (que afectan tanto a hombres como a mujeres) y que no es admisible desde el punto de vista del principio de ofensividad. En sentido diverso, Alonso ÁlAmo, «Protección penal de la igualdad y Derecho penal de género", Cuadernos de Política Criminal, (95), 2008, pp. 44 ss., al considerar que el bien jurídico adicionalmente vulnerado sería otro bien jurídico individual, que la citada autora identifica con " $l a$ igualdad" y que implicaría un mayor desvalor del resultado. Sin embargo, resulta paradójico y difícil de asimilar que el establecimiento y mantenimiento de una desigualdad penal -particularmente si su apreciación es meramente automática y ajena a las circunstancias del caso concreto- sirva y sea útil realmente para proteger la igualdad.

${ }^{21}$ Apoyada igualmente en la perseguibilidad de oficio de los delitos de violencia de género leve y ocasional, en la obligatoriedad de las órdenes de alejamiento y de las penas de prohibición de aproximarse a la víctima, en la irrelevancia de su consentimiento para valorar el quebrantamiento de condena, así como en la prohibición de la mediación, circunstancias todas ellas que redundan de la privación de la propia autonomía de las mujeres, como señalan AÑón RoIG, «Violencia de género: un concepto jurídico intricado» en MARTÍNEZ GARCÍA (dir.), La prevención y erradicación de la violencia de género: un estudio multidisciplinar y forense, Aranzadi, 2012, p. 44; VillaCAMPA Estiarte, Política criminal española en materia de violencia de género. Valoración crítica, 2018, pp. 222 s.; LAURENZO CoPEllo, Estudios Penales y Criminológicos, (35), 2015, pp. 800 ss. (destaca esta autora que el modelo tutelar frecuentemente se vuelve contra las propias mujeres); y SANZ MulAS, $R P$, (43), 2019, pp. 142 ss. (quien considera, además, que se ha interpretado erróneamente la posición feminista que exigía la intervención penal en este asunto, pues "no
} 
irrelevante que el agresor sea machista o no, o que abuse de una posición de dominio sobre su pareja femenina o no. Solo cabe reconocerles entonces una función represiva contra los hombres que ejercen violencias leves si se ignora de modo absoluto el contexto en el que se producen. Asimismo, se puede acabar produciendo una lectura inconstitucional del precepto, aquella que precisamente trataba de soslayar el TC, por quedar basada la asimetría penológica exclusivamente en diferencias biológicas y no culturales: la agravación de la pena se aplica porque el sujeto activo es un hombre, no porque sea un hombre que conscientemente inserta su conducta en una pauta de dominación o de discriminación hacia las mujeres (lo cual se presume o no es objeto de prueba). En definitiva, al ignorar que existen diversas clases de violencia ${ }^{22}$ y tratarlas de modo monolítico y apriorístico, se acaba presuponiendo que todos los hombres que recurren al empleo de la violencia leve y ocasional comulgan con un desprecio absoluto hacia las mujeres, ya que en todo caso se les va a poder imponer una pena superior. ${ }^{23}$

El único medio para atemperar las graves consecuencias de un Derecho penal de máximos en este ámbito es a través de los tipos privilegiados y de las causas de justificación.

Se resalta en la STS 677/2018 la posibilidad de aplicar el tipo atenuado facultativo del art. 153.4 en atención a las circunstancias personales del autor y las concurrentes en la realización del hecho $^{24 / 25}$ (que no deja de ser un tipo de violencia de género, aunque privilegiado), así como también la posibilidad de valorar supuestos de legítima defensa completa o incompleta. Es decir, puede apreciarse, por ejemplo, la legítima defensa del hombre frente a una agresión de su mujer. Pero ¿puede justificarse en algún caso la violencia de género? Esto es lo que habría que afirmar cuando concurre el tipo del art. 153.1 y a la par la legítima defensa del art. 20.4. ${ }^{\circ}$. En frase lapidaria contenida en la STS 217/2019, de 25 de abril (el hecho de propinar dos bofetones a su mujer en estado de embriaguez para reanimarla constituye una conducta desproporcionada y violenta), se advierte en sentido opuesto: "No hay causa de justificación ante el maltrato", parangonando el eslogan de que no hay justificación ante el maltrato. Sin embargo, también esa afirmación es retórica, pues momentos antes, partiendo de que el empleo de la fuerza o la

necesariamente equivale a apoyar que se fuerce a la mujer a una solución exclusivamente penal” y que "la violencia contra las mujeres se ha judicializado de manera muy intensa, pero eso, desgraciadamente, no se ha traducido en una disminución”).

${ }^{22}$ LARRAURi PijOAN, Criminología crítica y violencia de género, 2018, pp. 44 s.; PÉREz MANZANo, RJUAM, (34), 2016, p. 41; RUEDA MARTÍn, «Cometer el delito por discriminación referente al sexo de la víctima y/o razones de género como circunstancia agravante genérica», RECPC, (21-4), 2019, p. 18; TAMARIT SUMALLA, El cronista del Estado Democrático y Social de Derecho, (77), 2018, p. 23 (considerando incluso que es prevalente la bidireccional).

${ }^{23}$ Vid. críticamente con dicha presunción ACALE SÁNCHEZ, REDUR, (7), 2009, p. 71; LA MISMA, en FARALDO CABANa (dir.), Género y sistema penal: una perspectiva internacional, 2010, p. 30. Como señala MolinA FERNÁNDEZ, «Desigualdades penales y violencia de género», Anuario de la Facultad de Derecho de la Universidad Autónoma de Madrid, (13), 2009, pp. 74 s., no parece muy plausible que el agresor en la mayor parte o en todos los casos (aunque en alguno pueda ser así) vea su acto y le dé el significado de un desprecio a la dignidad del colectivo femenino o que vengan dominados por una motivación genuinamente sexista.

${ }^{24}$ También LARRAUR PIJOAN, InDret, (1), 2009, p. 14 (según esta autora, los motivos por los cuales una agresión del hombre a su pareja femenina es generalmente más grave pueden no estar presentes, estando el juez autorizado en tal caso a "desviarse" de la norma precisamente en la fase de individualización de la pena).

${ }^{25}$ Sin que la STS $677 / 2018$ explique por qué no toma en consideración el tipo privilegiado para el caso concreto, como sí se hace en otras sentencias posteriores que han tenido que resolver sobre violencias bidireccionales: SAP de Murcia (sec. 3) 99/2019, de 12 de marzo; SAP de Pontevedra (sec. 4), 105/2019, de 20 de mayo. 
violencia constituye en toda clase de escenario y sin excepción violencia de género, había admitido que "el empleo de la violencia o de la fuerza no puede operar como causa de justificación, salvo casos concretos y debidamente motivados en atención a evitar un mal mayor a la víctima que el que se ejerce con la agresión" (en el supuesto enjuiciado no concurría por entenderse desproporcionados los dos bofetones a la mujer y existir medios alternativos menos perjudiciales).

Pues bien, de acuerdo con la tesis objetivista del TS, previo a comprobar los requisitos de la causa de justificación de legítima defensa, habría que afirmar que concurre el tipo del art. 153.1 y que, por tanto, estamos ante un hecho constitutivo de violencia de género. Sin embargo, la subsunción en el tipo de violencia de género, por estimar que reproduce una pauta de dominación masculina y que es más grave per se, entra en abierta contradicción con el hecho de que el acto de violencia no sea agresivo, sino meramente defensivo. Una primera consecuencia de aquella subsunción típica afectaría en el ámbito de la causa de justificación a la necesidad racional del medio empleado interpretado en términos de proporcionalidad (frente al acto de maltrato de la mujer no estaría justificado un acto defensivo de la misma naturaleza o entidad, pues idéntico comportamiento externo recibe en la ley un tratamiento penológico diferenciado según lo realice la pareja masculina o la femenina). Lo coherente sería estimar que el hecho no responde a una manifestación de la violencia de género, sino a algo distinto cuya tipicidad reside en este caso en los tipos comunes. Solo si la eximente de legítima defensa fuera incompleta (por existir provocación suficiente por parte del hombre o por no ser racionalmente necesario el medio empleado para impedir o repeler la agresión ilegítima), podría afirmarse que el hecho violento, aunque defensivo en su intención, responde a una pauta sociocultural machista o de género (al haber provocado la agresión de la mujer o al haberse excedido en la reacción defensiva, demostrando de ese modo el abuso de una posición de dominio).

Aunque es muy difícil encontrar un ejemplo práctico de lo acabado de exponer, es decir, de la posible concurrencia de una causa de justificación con relación a sucesos mínimamente violentos en el ámbito relacional de la pareja, un supuesto, al menos análogo, lo encontramos en la SAP de Cantabria (sec. 3) 121/2013, de 25 de marzo. Un sujeto había sido condenado por el delito del art. 153.1 por el hecho de empujar para que se marchara a la mujer que acudió a su domicilio con el propósito de reanudar la relación y que se negó a abandonarlo cogiendo unas tijeras. Aunque pudo y debió haber estimado un estado de necesidad como causa de justificación en defensa de la morada (de acuerdo con el art. 20.4. ${ }^{\circ}$, primero, solo cabe la legítima defensa para impedir la entrada indebida en la morada, pero no la permanencia contra la voluntad del morador), el tribunal de apelación apreció la inexistencia de la tipicidad del comportamiento: "Tal descripción de hechos no constituye un delito de violencia de género en su modalidad de maltrato, puesto que la razón de que la empujara no fue agredirla, sino hacerla salir de su casa, que es cosa bien distinta", no existiendo, además, otras pruebas de cargo sobre lesiones igualmente denunciadas. ${ }^{26}$

\footnotetext{
${ }^{26}$ Describe un caso muy similar Pérez MANZANo, RJUAM, (34), 2016, p. 41, n. 39, que cita la Sentencia del Juzgado de lo Penal núm. 3 de Getafe (Madrid) 422/2013, de 30 de diciembre de 2013 con el siguiente supuesto de hecho: “A, varón, se encuentra a su ex pareja B, mujer, en su cama, después de que ésta haya entrado sin permiso en casa de A por una ventana. Como B se niega a abandonar la casa, A recoge sus cosas y las pone en el rellano de la escalera, momento en el que es atacado por B. En esta situación, A reacciona sujetando a $B$ de los brazos y empujándola, lo que provoca la caída de $B$ al suelo. Se da la circunstancia de que hacía poco que A había puesto fin a la relación y B se negaba a que la relación
} 
La cuestión, por tanto, es si se puede considerar aceptable un Derecho Penal objetivista en los delitos de violencia de género. Y la respuesta es que no, porque se incurren en incoherencias dogmáticas insalvables y se lleva innecesariamente hasta límites peligrosos algunos de los principios básicos del Derecho (igualdad), del Derecho Penal (culpabilidad) y Derecho ProcesalPenal (presunción de inocencia). Y no es que no se pueda recurrir al Derecho Penal para luchar contra la violencia de género, lo que no debería en ningún caso es hacerse desde puntos de partida maximalistas dirigidos a presentar la diversidad del comportamiento humano de un modo estandarizado, con arreglo a roles o patrones preestablecidos normativamente ${ }^{27}$ (y que se acaban perpetuando pese a que se quieren erradicar), pues ello se traduce en un Derecho Penal poco atento a lo injusto personal y a la culpabilidad individual (al resultar prácticamente irrelevante investigar las circunstancias del caso concreto para calificar una conducta como violencia de género) y, por tanto, en algo que puede no ser ni justo ni riguroso.

En cuanto a lo injusto personal, aun cuando lo que importa desde ese punto de vista (desvalor de la acción y desvalor del resultado) es la objetividad del acto y su aspecto sociológico, es evidente que el sujeto activo al menos tendrá que tener conciencia de que su comportamiento no es ajeno por completo al significado objetivamente más grave que las leyes le atribuyen en cuanto reproduce una pauta de dominación machista (ello con independencia de que en el caso concreto exista dominación y/o motivación machista). ${ }^{28}$ De otro modo la mayor gravedad de lo injusto residiría exclusivamente en el desvalor del resultado objetivo basado en el significado sociológico de un comportamiento, sin pasar por el desvalor de la acción. Pues bien, ¿por qué esta conciencia acompañante no puede ser descartada en algún caso? Desde luego el automatismo lo impide.

Del mismo modo, en la culpabilidad individual por la conducta antijurídica al sujeto se le reprocha haber actuado pese a tener conciencia de la mayor gravedad de su comportamiento (al cometerse en ámbito de la pareja y contra una mujer). Si además fue reprochable su motivación sexista, ello tendría que servir de motivo para fundamentar la agravación de su conducta. Pero si se resuelve el problema imputando en lo injusto al sujeto un mayor desvalor del resultado puramente objetivo, sin que esté necesariamente abarcado por el desvalor de la acción (dolo en el sentido al menos de conciencia irreflexiva o acompañante), ¿cómo se le puede reprochar al sujeto un plus de injusto objetivo ajeno a su conciencia sin vulnerar el principio de culpabilidad?

concluyera”. Dicho supuesto lo considera la citada autora un ejemplo de violencia leve ocasional que no obedece a un patrón de violencia de género.

${ }^{27}$ Estereotipos legalizados en los que no cabe la corrección judicial negativa, a pesar de que la mayoría de las agresiones ocasionales realizadas sobre las mujeres no obedece a razones de género basadas en la desigualdad, la discriminación y las relaciones de poder, como destaca SANZ MULAS, Violencia de género y Pacto de Estado, La huida hacia delante de una norma agotada (LO 1/2004), 2019, p. 54.

${ }^{28}$ De ello parece partir el TC cuando indica que en absoluto se está sancionando al sujeto activo por lo que es, o por ser varón, sino "por el especial desvalor de su propia y personal conducta: por la consciente inserción de aquélla en una concreta estructura social a la que, además, él mismo, y solo él, coadyuva con su violenta acción" (STC 59/2008, F. 11). Pero, como dice Molina FERnÁNDEZ, (Anuario de la Facultad de Derecho de la Universidad Autónoma de Madrid, (13), 2009, p. 75), si bien el planteamiento teórico es correcto, mucho más problemática es la cuestión fáctica si de esa circunstancia se da efectivamente en la violencia en la pareja: que la mujer se vea a sí misma al ser agredida como parte del colectivo de las mujeres y el hombre a sí mismo como parte del colectivo de los hombres, y ambos representando los roles arcaicos atribuidos a cada sexo por la cultura dominante del varón. 
El hecho de admitir la existencia de excepciones en el art. 153.1 y derivarlas al art. 153.2 ó 4 (tipo básico y tipo privilegiado respectivamente) para ciertos casos de violencias sin lesión bidireccionales, no representa un paso atrás, sino que constituye una adecuación de los tipos de violencia de género al fenómeno que se quiere combatir. En cambio, con el automatismo y la renuncia a la excepción se pueden acabar imponiendo penas más graves que las que corresponderían al caso concreto, sin conexión con lo injusto ni con la culpabilidad, y solo en atención a consideraciones preventivo-generales, dando lugar a que el tipo del art. 153.1 pueda incurrir, como pone de manifiesto MOLINA FERNÁNDEZ, en una sobreinclusión contraria al principio de proporcionalidad. ${ }^{29}$ Dicho con otras palabras de ACALE SÁNCHEZ, "debe entenderse que la labor judicial de aplicación de la norma al caso concreto no es meramente matemática” y que "la necesidad de «probar» los hechos con sus respectivos elementos objetivos y subjetivos no debe ser temida: no es más que el fruto del Estado de Derecho diseñado por nuestra Constitución que consagra la presunción de inocencia como un derecho fundamental del ciudadano y la necesidad de desvirtuarla”. ${ }^{30}$

Por otro lado y como se ha destacado en la doctrina, ${ }^{31}$ los tipos que comprenden violencias fugaces $\mathrm{u}$ ocasiones no son los que mejor sirven para captar el problema de fondo que en la mayor parte de los casos subyace o puede subyacer, esto es, que tales conductas no son tan aisladas como se presentan, en detrimento del tipo de lo injusto que tal vez mejor se adapta a las circunstancias cuya prueba en el caso concreto se demanda, esto es, la existencia de una situación de dominación o de desequilibrio estructural, y que no es otro que el delito de violencia habitual del art. 173.2 CP. ${ }^{32}$ Hasta el punto que, según señala SANZ MULAS, el apremio por castigar los actos leves de maltrato desalienta muchas veces a los tribunales a investigar las situaciones graves de violencia. ${ }^{33}$ Ello, además, cuando en realidad el fenómeno criminal que se trató de combatir por la LO 1/2004 con el establecimiento de tipos de violencia relacional, producidos de forma puntual, leve y ocasional, no era otro que intervenir sobre una clase de

${ }^{29}$ Molina Fernández, Anuario de la Facultad de Derecho de la Universidad Autónoma de Madrid, (13), 2009, pp. 65, 79 ss., 85. Considera este autor que presuponer que no caben agresiones en la pareja sin el contexto que justifica la agravación es tan inverosímil como afirmar que no es posible que un heterosexual agreda a un homosexual sin tintes homófobos o un blanco agreda a un negro sin que la acción esté necesariamente impregnada de tintes racistas. Vid. también RuIz Miguel, Jueces para la Democracia, (55), 2006, pp. 43 s., quien, redundando en que es insuficiente para sancionar más gravemente a un determinado colectivo atender exclusivamente a razones preventivas, añade que "por raros que puedan resultar, no resultan impensables casos de agresiones leves a la mujer por su pareja claramente ajenos a la violencia de género". A su modo de ver, "esta posibilidad obliga a entender que la presunción establecida por la Ley Integral ha de considerarse derrotable o excepcionable o, por decirlo en el lenguaje más familiar a los juristas, debe tomarse como una presunción iuris tantum, porque de no hacerlo así se resentiría el principio de culpabilidad penal por castigar a quien realiza una conducta ajena a los motivos de agravación de la pena”.

${ }^{30}$ ACALE SÁNCHEZ, Jueces para la Democracia, (92), 2018, p. 28 y LA MISMA, en MARTín SÁNCHEZ (dir.), Estudio Integral de la Violencia de Género: un análisis teórico-práctico desde el Derecho y las Ciencias Sociales, 2018, p. 438.

${ }^{31}$ Laurenzo Copello, Estudios Penales y Criminológicos, (35), 2015, p. 821.

${ }^{32}$ En la Macroencuesta de violencia contra la mujer de 2015, disponible en internet, se pone de manifiesto que solo el 12,6\% de las mujeres que ha sufrido violencia física de alguna pareja o expareja a lo largo de su vida afirmó que se trató de un hecho aislado, mientras que un 85,2 \% manifestó haber sido víctima de agresiones físicas en más de una ocasión (p. 30); en el caso de violencia sexual las cifras respectivas son $3,5 \%$ y $94 \%$.

${ }^{33}$ SANZ MulAS, Violencia de género y Pacto de Estado, La huida hacia delante de una norma agotada (LO $1 / 2004), 2019$, p. 59, quien destaca que el $70 \%$ de los casos que llegan a los tribunales se califican como violencia leve, y solo el 10\% se instruye como violencia habitual. También LARRAURI PIJOAN, Criminología crítica y violencia de género, 2018, pp. 108 s. 
violencia que se reitera en el tiempo y que tiende a ir aumentando la intensidad ${ }^{34}$ finalidad que debería haber conducido a diferenciar entre los casos leves, puntuales y aislados, ajenos a un contexto de dominación, discriminación y poder en la pareja, de aquellos otros en los que el supuesto puntual y aparentemente aislado no es tan leve, porque se enmarca en un contexto, clima o ambiente en la relación -lo que supone cierta perduración o prolongación en el tiempo- de abuso de una posición de poder. Por otra parte, la figura delictiva de violencia doméstica habitual sorprendentemente no se configura como un tipo de violencia de género, sino de violencia doméstica, por lo que debería poder apreciarse la agravante de género en aquellas hipótesis en las que concurra, además, la motivación machista del autor. ${ }^{35}$ Sin embargo, no parece que sea éste el campo que se le atribuye a dicha agravante por parte de un sector muy reciente de la jurisprudencia, y menos aún que la motivación del autor sea un elemento de dicha circunstancia cuando el autor del delito tiene o ha tenido una relación de pareja con la víctima, como veremos en el próximo epígrafe.

\section{La irrupción de la agravante de género}

La circunstancia agravante del.$^{\circ} 4$ del art. 22, de "cometer del delito ... por razones de género", que fue introducida por la LO $1 / 2015$, de 30 de marzo, ${ }^{36}$ habilita un nuevo procedimiento para combatir la violencia de género no solo en la pareja, sino también fuera de ella. Por un lado, los tipos de violencia de género de la LO 1/2004 se limitan a unas figuras delictivas muy concretas y aunque dicha ley proclama en su art. 1.3 que la violencia de género a que se refiere comprende todo acto de violencia física y psicológica, incluidas las agresiones a la libertad sexual, las amenazas, las coacciones o la privación arbitraria de libertad, en realidad quedaron al margen de toda referencia al género la mayor parte de las figuras delictivas contenidas en el $\mathrm{CP}$, entre ellas los delitos contra la vida, la libertad sexual, la libertad ambulatoria, la integridad moral, la intimidad o, incluso, no tan personalísimos como el patrimonio. Sin embargo, una vez incluida entre las circunstancias agravantes las razones de género, sería posible abarcar completamente el conjunto de delitos que un hombre es capaz de cometer contra su pareja femenina por motivos discriminatorios en razón de su género, al margen de aquellos en los que tal relación constituye un elemento esencial del delito ${ }^{37}$ (y del que podría haberse prescindido en la reforma para mantener la unidad del sistema). ${ }^{38}$ Por otro lado, dado que la agravante no limita los sujetos activo y pasivo al hombre o a la mujer, y menos aún a que sean o hayan sido

\footnotetext{
${ }^{34}$ Vid. al respecto ACALE SÁNChEZ, en MARTín SÁNChEZ (dir.), Estudio Integral de la Violencia de Género: un análisis teórico-práctico desde el Derecho y las Ciencias Sociales, 2018, p. 409.

35 Vid. en este sentido SAN MiLlán FERnÁNDEZ, «Estudio dogmático y jurisprudencial sobre la agravante de discriminación por razones de género», Estudios Penales y Criminológicos, (39), 2019, p. 344; SERRANO GONZÁLEZ DE MURILLO, «Violencia machista y circunstancia mixta de parentesco», RP, (44), 2019, p. 211.

${ }^{36}$ Antecedentes de esta circunstancia figuraban en el CP desde la LO 15/2003, de 25 de noviembre, que incorpora el delito de lesa humanidad definido como el ataque o persecución sistemático o generalizado de un grupo por motivos, entre otros muchos, de género, tomando como modelo el delito recogido en el Estatuto de Roma de la Corte Penal Internacional: art. 7.1.h). Al respecto, Carreras Presencio, Concepto jurídico de violencia de género, 2019, pp. 105 ss.

${ }^{37}$ Desde la reforma del CP de 2015 se ha eliminado del mismo toda referencia a los "delitos de violencia de género”, que se empleaba en sede de suspensión y sustitución de las penas privativas de libertad, y se ha sustituido por la de "delitos cometidos sobre la mujer por quien sea o haya sido su cónyuge, o por quien esté o haya estado ligado a ella por una relación similar de afectividad, aun sin convivencia”, de manera que no puedan surgir dudas hermenéuticas sobre el alcance de aquella referencia, que es más amplia que la que se deriva de la LO 1/2004; vid. Alastuey Dobón/EsCUChuri AisA, RDP, (23), 2015, p. 40.

${ }^{38}$ Vid. a este respecto BOLEA BARDón, «En los límites del Derecho Penal frente a la violencia doméstica y de género», RECPC, (9-2), 2007, pp. 23 s., n. 43.
} 
pareja, su tenor literal permite en principio que pueda apreciarse también cuando entre el sujeto activo y pasivo no media relación alguna, ni de pareja ni de ninguna otra clase, pero el delito se ha cometido por razones de género.

Explica el legislador en el Preámbulo de dicha ley que "el género, entendido de conformidad con el Convenio n. ${ }^{\circ} 210$ del Consejo de Europa sobre prevención y lucha contra la violencia contra las mujeres y la violencia doméstica, aprobado en Estambul por el Comité de Ministros del Consejo de Europa el 7 de abril de 2011, como «los papeles, comportamientos o actividades y atribuciones socialmente construidos que una sociedad concreta considera propios de mujeres o de hombres», puede constituir un fundamento de acciones discriminatorias diferente del que abarca la referencia al sexo". Y, en efecto, aunque inicialmente esta nueva agravante se solapa en parte con la de discriminación por razón del sexo, que literalmente hace referencia a las características biológicas y fisiológicas que diferencian a los hombres de las mujeres (STS $420 / 2018$, de 25 de septiembre), y de la que tan escaso uso se ha realizado a pesar de figurar en el CP desde $1995,{ }^{39}$ aquélla, por sus connotaciones culturales sobre los roles socialmente atribuidos a hombres y mujeres, tiene un contenido propio específico que va más allá de una característica biológica, y desde un punto de vista práctico mucha mayor aplicabilidad que la de sexo, cuyo campo de actuación queda aún más constreñido, convirtiéndose, si ya no lo era, en una circunstancia marcadamente simbólica y residual. ${ }^{40}$ Será muy difícil hallar un supuesto de la práctica en el que la discriminación por razón de sexo se encuentre a su vez desprovista de contenidos o referencias al género.

En primer lugar, conviene aclarar que el Convenio de Estambul no prevé ni exige de modo explícito o implícito el establecimiento de una agravación basada en el género, como sugiere la jurisprudencia más reciente siguiendo la STS 565/2018, de 19 de noviembre. En aquél la agravante de género no se menciona y la mayor parte de las agravantes que contempla en su art. 46 (para que puedan ser tomadas en consideración en el momento de la determinación de las penas, y siempre que no sean de por sí elementos constitutivos del delito) no guardan relación ni directa ni indirecta con la agravante por razones de género. ${ }^{41}$ La única que se

\footnotetext{
${ }^{39}$ Apenas se encuentran resoluciones que la refieran [vid. MARín DE EsPINOSA CEBALLOS, «La agravante genérica de discriminación por razones de género (art. 22.4 CP)», RECPC, 20-27, 2018, pp. 9 ss., alude a dos ocasiones en que ha sido alegada en causas seguidas por asesinato ante Audiencias Provinciales, para posteriormente ser rechazada]. Por nuestra parte, solo hemos podido hallar un único supuesto en el que se aplica la agravante de sexo en un caso de robo con violencia y falta de lesiones (SJP de Barcelona n. 9 287/2015, de 10 de junio).

${ }^{40}$ Así JERICó OJER, «Perspectiva de género, violencia sexual y Derecho Penal», en Monge FernÁNDEZ (dir.), Mujer y Derecho Penal. ¿Necesidad de una reforma desde una perspectiva de género?, Bosch Editor, 2019, pp. 318 s. Para Rebollo VARgas, «La agravante de discriminación por razón de sexo y su fundamento (art. 22.4 del Código Penal)», RGDP, (23), 2015, p. 15, no es comprensible que se siga manteniendo.

${ }^{41}$ Las restantes circunstancias incluidas en dicho precepto son las siguientes:

a) (...) por un miembro de la familia, una persona que conviva con la víctima o una persona que abuse de su autoridad;

b) que el delito, o los delitos conexos, se haya cometido de forma reiterada;

c) que el delito se haya cometido contra una persona que se encuentre en situación de vulnerabilidad por

la concurrencia de particulares circunstancias;

d) que el delito se haya cometido contra o en presencia de un menor;

e) que el delito se haya cometido por dos o más personas actuando conjuntamente;

f) que el delito haya sido precedido o se haya acompañado de una violencia de extrema gravedad;

g) que el delito se haya cometido mediante la utilización o la amenaza de un arma;

h) que el delito haya provocado graves daños físicos o psicológicos a la víctima:

i) que el autor haya sido condenado anteriormente por hechos de similar naturaleza.
} 
asemeja es la circunstancia agravante del primer inciso de la letra a) "que el delito se haya cometido contra un cónyuge o pareja de hecho actual o antiguo, de conformidad con el derecho interno (...)". Sin embargo, este ámbito relacional, de por sí más grave (pues implica generalmente relaciones de parentesco) y en razón de ello agravado, tan solo comprende una de las posibles manifestaciones de la "violencia contra las mujeres por razones de género", concepto mucho más amplio que define la violencia contra las mujeres por razones de género como "toda violencia contra la mujer porque es mujer o que afecte a las mujeres de manera desproporcionada", conforme al art. 3.d) del Convenio. Sin embargo, no se anuda a ella una consecuencia penal específica en forma de agravante o de elemento constitutivo del tipo de delito alguno. Por el contrario, a partir de esta definición, como señala SERRANO GONZÁLEZ DE Murillo, el convenio enumera una serie de conductas que deben ser en todo caso previstas como delito en los CCPP de los Estados signatarios, en cuanto se trata de conductas que se pueden cometer contra la mujer por ser mujer o que les afecta a las mujeres de manera desproporcionada, de modo que no tiene sentido imponer, además del delito correspondiente, una agravante de género ${ }^{42} \mathrm{o}$, al menos, no automáticamente. Es más, el art. 43 proclama que "los delitos previstos en el presente Convenio se sancionarán con independencia de la relación existente entre la víctima y el autor del delito". De ello puede deducirse que ni los tipos constituidos sobre el género de la víctima ni la agravante basada en el género femenino de la víctima sean exigencias derivadas del aludido convenio, sino que la decisión de tipificar de manera agravada o, de otro modo, agravar la pena del delito mediante una circunstancia queda a la discreción del Derecho interno de los Estados, ${ }^{43}$ cuyas prescripciones deberán ser interpretadas en todo caso a la luz de las definiciones del convenio. Tanto es así que, entre las reservas que contempla dicho instrumento normativo internacional, se encuentra el derecho de los Estados a prever sanciones no penales con respecto a la violencia psicológica y al acoso (art. 78.3), además de no imponer la persecución de oficio de los delitos de violencia contra la mujer (art. 55). ${ }^{44}$ ¿Cómo iba a prever el convenio una agravante común o general de género si algunas conductas que forman parte del elenco de manifestaciones de la violencia contra la mujer que en él se contemplan pueden no ser ni siquiera consideradas delito por parte de algún Estado?

Ciertamente esta clase de cualificaciones penales mediante elementos típicos o circunstancias agravantes basados en el género tendrían un apoyo genérico en otras iniciativas internacionales previas, aunque ninguna promueve la discriminación penológica por géneros. Así, la recomendación n. ${ }^{\circ} 19$ del Comité de la Convención sobre la eliminación de todas las formas de discriminación contra la mujer, de 29 de enero de 1992, alude a que los Estados adoptarán todas las medidas jurídicas y de otra índole necesarias para prestar protección eficaz a las mujeres contra la violencia dirigida a ellas (comprensiva de la violencia y los malos tratos en la familia, el ataque sexual y el hostigamiento sexual en el lugar de trabajo), "incluidas entre otras las sanciones penales". Sin embargo, la forma de articular dichas sanciones, y si en todo

\footnotetext{
${ }^{42}$ Serrano GonZÁlez de Murillo, RP, (44), 2019, pp. 200 s.

${ }^{43}$ El Informe explicativo del Convenio de Estambul se expresa en este sentido: "Los redactores acordaron que, en principio, todas las disposiciones de Derecho penal de la Convención deberían ser presentadas de manera neutral respecto al género; el sexo de la víctima o el perpetrador no debe, por lo tanto, en principio, ser un elemento constitutivo del delito. Sin embargo, esto no debería impedir a las Partes la introducción de disposiciones específicas de género". Vid. «Explanatory Report to the Council of Europe Convention on preventing and combating violence against women and domestic violence», Council of EuropeTreaty Series, n. ${ }^{\circ}$ 210, 2011, p. 23 (n. $\left.{ }^{\circ} 153\right)$.

${ }^{44}$ Como destaca Villacampa Estiarte, «Pacto de estado en materia de violencia de género: ¿más de lo mismo?», RECPC, (20-4), 2018, p. 11.
} 
caso pueden o deben representar un plus en la sanción exclusivamente cuando la víctima es una mujer y el autor un varón, no se explicita en ninguna norma internacional.

Pues bien, salvo España, los Estados nacionales de nuestro entorno no han dado el paso que en su momento representó en nuestro país la tipificación de figuras específicas de violencia de género en la pareja en 2004. A lo sumo han preferido recurrir al ámbito de las circunstancias agravantes como elementos que cualifican la conducta y la sanción penal, pero sin fijar un sexo o un género específico de la víctima en aquellos delitos cuyo sujeto activo y pasivo puede ser cualquiera $^{45}$ (al margen pues de figuras delictivas marcadas por el género de la víctima como la mutilación genital femenina, y del que puede ser autor tanto el hombre como la mujer).

En nuestra particular tradición jurídica, que reconoce desde 2004 la existencia de delitos en los que la relación de género es consustancial al delito mismo, en principio no tendría que resultar incoherente la inserción de una agravante genérica o común de género que sea aplicable a la generalidad de los delitos contra las personas. Si se puede lo más (que el género aparezca como elemento constitutivo del tipo), se puede lo menos (que el género constituya elemento accidental del delito). Con ello, además, se estaría logrando traspasar el estrecho marco de la violencia en la pareja en el que quedó recluido inicialmente el concepto de género en nuestra legislación para extenderlo a la violencia contra la mujer en cualquier ámbito de la comunidad $\mathrm{y}$ en cualquier figura delictiva en la que proceda apreciar el carácter discriminatorio del comportamiento (cuando concurran los requisitos de la circunstancia y esté excluida cualquier relación de inherencia con el delito).

Ahora bien, por un lado, esta circunstancia genera dificultades de delimitación con otras agravantes comunes del delito y con los propios tipos cualificados, siendo necesario realizar juicios de inherencia de la circunstancia con los delitos en los que se plantea su aplicación o de compatibilidad con otras circunstancias agravantes, lo que pone en evidencia que el CP adolece de numerosos defectos técnicos al haberse legislado en los últimos años de un modo asistemático y sin visión de conjunto. ${ }^{46}$ Posiblemente, habría sido preferible desde este punto de vista optar por uno u otro modelo, pero no mezclarlos: ${ }^{47} \mathrm{o}$ bien que el género constituya un

\footnotetext{
${ }^{45}$ Por ejemplo, el CP francés, que desde 2010 contiene en el art. 132-80 una agravante cuando los actos se cometen en el ámbito de la pareja o expareja (aplicable a ambos sexos), establece también desde la Ley de 27 de enero de 2017 una nueva agravante en el art. 132-77 del CP cuando el delito sea precedido, acompañado o seguido de palabras, escritos, imágenes, objetos o actos de cualquier tipo que perjudiquen el honor o la consideración de la víctima o de un grupo de personas de las cuales la víctima sea miembro, debido a su sexo, orientación sexual o identidad de género, verdadera o supuesta, o se establezca que los actos fueron cometidos contra la víctima por una de estas razones. Dicha elección, que prescinde de que el sujeto pasivo sea necesariamente mujer, se considera, no obstante, insuficiente en atención a la naturaleza específica de la violencia contra las mujeres; vid. LERAY/MONSALVE, «Un crime de féminicide en France? A propos de l'article 171 de la loi relative à l'égalité et à la citoyenneté», Revue du Centre de recherches et d'études sur les droits fondamentaux, Actualités Droits-Libertés, fev. 2017. Por su parte, en el Código penal italiano, la Ley de 15 octubre de 2013, n. ${ }^{\circ} 119$, introdujo sendas agravantes en los delitos de violencia sexual y de acoso en relaciones de pareja, y, más recientemente, mediante la Ley de 19 de julio de 2019, n. $^{\circ}$ 69, en materia de tutela de la víctima de violencia de doméstica y de género, se incorpora una agravación equivalente en los delitos de difusión ilícita de imágenes o videos sexualmente explícitos, pero no prevé una agravante común de género. Tampoco en el Código penal alemán se menciona el género de la víctima como elemento agravante o cualificado. El legislador alemán se ha limitado a reformar en 2016 los delitos sexuales desde una perspectiva de género, pero ni siquiera existe en Alemania una definición legal para la violencia doméstica.

${ }^{46}$ Serrano GonzÁlez de Murillo, RP, (44), 2019, pp. 208 ss.

${ }^{47}$ Vid. en este sentido ACALE SÁNCHEZ, en MARTín SÁNCHEZ (dir.), Estudio Integral de la Violencia de Género: un análisis teórico-práctico desde el Derecho y las Ciencias Sociales, 2018, pp. 419 y 438, quien se cuestiona
} 
elemento típico específico de todos aquellos delitos que pueden ser manifestación de la violencia contra la mujer por razones de género, o bien que el género se presente en todos ellos como simple circunstancia agravante. Por otro lado, esa inicial coherencia, basada en la complementariedad de la agravante de género con los tipos de violencia de género y en la identidad de un fundamento común, enseguida se pone en cuestión, porque el carácter de género de los tipos se aprecia por la jurisprudencia de manera puramente objetiva y mecánica, mientras que la circunstancia agravante posee naturaleza subjetiva, pues se basa en la motivación, y ésta debe probarse en el caso concreto. Es decir, los mecanismos para aplicarlas resultan completamente antagónicos, desbaratando cualquier juicio de inherencia entre la circunstancia de género y el tipo de violencia de género correspondiente. Asimismo, saltan a la vista lo que aparentemente son discordancias penológicas derivadas de mantener un doble criterio con el género (que se emplea como elemento del tipo y como circunstancia agravante según los casos), tales como que el efecto agravante de una sola circunstancia pueda ser superior al del mismo factor elevado a la categoría de elemento esencial del tipo. Así, en el delito del art. 153, la pena resultante del tipo básico -la violencia doméstica ocasional del art. 153.2 - con el añadido de la circunstancia de género (sin que concurran atenuantes), en virtud del art. 66.1.3. ${ }^{a}$, es superior a la que está prevista en el tipo cualificado (al que resultan inherentes las agravantes de género y parentesco). ${ }^{48}$ Esto relativiza el efecto de una agravante sobre la pena frente al que tiene un elemento que sirve para configurar un tipo agravado o cualificado. Máxime cuando en general en los delitos representativos de violencia contra la mujer pueden ser aplicables al delito cometido dos o más circunstancias agravantes (en particular y en atención a la condición de la víctima como mujer: género, parentesco o abuso de superioridad) que, de ser aplicables al tipo básico, podrían elevar la pena tanto o más que la de un tipo cualificado. ${ }^{49}$

De ahí que la alternativa sugerida desde un primer momento por la doctrina de castigar mediante una agravante de motivos sexistas o machistas, en lugar de hacerlo mediante figuras

si tiene sentido el modelo instaurado en 2004 o, incluso, si realmente existe un modelo, porque "no es posible mantener tipos penales leves en los que se impone más pena al hombre que victimiza a su mujer, a la vez que se incorporan nuevos tipos no sexuados, porque o se eliminan los delitos incorporados al Código en 2004, o se sexualizan los llegados al mismo en 2015”. En la medida en que la agravante de género permite llegar aún más allá que los tipos penales de género, la autora se inclina por suprimir las referencias expresas en los arts. 148, 153, 171 y 172 a la mujer víctima.

${ }^{48}$ La mitad superior de una pena tres meses a un año de prisión o trabajos en beneficio de la comunidad de 31 a 80 días -que es la pena del tipo básico de violencia doméstica respectiva del art. 153.2- es la pena de prisión de siete meses y dieciséis días a un año o trabajos en beneficio de la comunidad de 56 a 80 días; por lo tanto, es superior a la prevista en el art. 153.1 (el tipo cualificado), esto es, prisión de seis meses a un año de prisión o trabajos en beneficio de la comunidad de 31 a 80 días. Vid. a este respecto AcALE SÁNCHEZ, en MARTÍN SÁNCHEZ (dir.), Estudio Integral de la Violencia de Género: un análisis teórico-práctico desde el Derecho y las Ciencias Sociales, 2018, p. 422, que también pone en evidencia esta circunstancia penológica que puede acabar beneficiando al autor a efectos de pena, porque -como apunta la citada autora- "la criminalización expresa determina la solución de un posible concurso de normas que se planteara a favor de la ley especial” (tipo básico + agravante versus tipo cualificado).

${ }^{49}$ De ahí que, como dice PÉrez MANZANo, Revista Jurídica Universidad Autónoma de Madrid, (34), 2016, p. 49, aunque la violencia de género presente un desvalor singular, "no es exigible del legislador, ni probablemente posible, una precisión tan matemática e individualizada en la valoración de la gravedad de los hechos delictivos que sanciona. Una regulación razonable es la que configura marcos de pena que habilitan opciones para que el juez valore la singularidad de cada caso individual en una comparación aproximada con otros hechos”. 
típicas cualificadas, se evidencie a día de hoy también como la alternativa preferida ${ }^{50}$ Ello, entre otras cosas, porque al tratarse de una circunstancia agravante general y común a todos los delitos, tiene un campo de aplicación muy superior al de la tipificación expresa de unos pocos delitos, como sucede con los de violencia de género, que no son los únicos de su especie y ni siquiera entre ellos se incluyen los más representativos o de mayor resonancia en esa clase de violencia (como son los delitos de homicidio y asesinato).

El hecho es que en la práctica jurisprudencial desde su incorporación al CP se ha apreciado la agravante por razones de género en numerosas ocasiones, fundamentalmente en delitos cometidos en el seno de relaciones actuales o pasadas de pareja -muchos en procesos de ruptura- en los que la referencia al género, aunque sociológica, carecía de una traducción jurídica entre los elementos del delito o en la penalidad (más allá de la relación de parentesco, si concurría). Hacemos referencia sobre todo a la aplicación de la agravante de género a delitos de homicidio, asesinato, detención ilegal y agresión sexual.

Como indica la STS 420/2018, de 25 de septiembre, "con la introducción de la agravante relativa a cometer el delito por una discriminación basada en razones de género, se amplía esta protección con carácter general, de modo que la agravación de la pena no solamente es procedente en los casos expresamente contemplados en las descripciones típicas de la parte especial, en los que las razones de la agravación ya viene contemplada en el tipo, sino en todos aquellos otros casos en los que la discriminación por esas razones, basadas en la intención de dominación del hombre sobre la mujer, que dentro de las relaciones de pareja es considerada por el autor como un ser inferior, vulnerando, por lo tanto, su derecho a la igualdad, aparezcan como motivos o móviles de la conducta”. ${ }^{51}$

Junto a ella, y por ser la víctima la pareja o expareja femenina del autor, se ha apreciado también en esos delitos comunes la circunstancia agravante de parentesco en relación de compatibilidad con aquélla. ${ }^{52}$ Para ello se parte, en primer lugar, de su distinto fundamento.

\footnotetext{
${ }^{50}$ Inicialmente así: ACALE SÁNCHEZ, La discriminación hacia la mujer por razón de género en el Código penal, 2006, pp. 411 ss.; LA MISMA, en FARALDO CABANA (dir.), Género y sistema penal: una perspectiva internacional, 2010, p. 30; Comas D’ARgemir CENDrA, «La Ley Integral contra la Violencia de Género. Nuevas vías de solución», en BOLDOVA PASAMAR/RUEDA MARTÍN (coords.), La reforma penal en torno a la violencia doméstica y de género, 2006, p. 50; QUERALT JIMÉNEZ, «La última respuesta penal a la violencia de género», La Ley, (1), 2006, pp. 1423 ss.; Alonso Álamo, Cuadernos de Política Criminal, (95), 2008, pp. 51 s.; Molina FernándeZ, «Desigualdades penales y violencia de género», p. 78. De manera más reciente, una vez se cuenta con la agravante de género en el CP: VILLACAMPA ESTIARTE, «Pacto de estado en materia de violencia de género: ¿más de lo mismo?», RECPC, (20-4), 2018, p. 13; LA MISMA, Política criminal española en materia de violencia de género. Valoración crítica, 2018, pp. 88 y 217; SERRANo GonzÁlez DE Murillo, RP, (44), 2019, p. 213; Alonso Álamo, en Monge Fernández (dir.), Mujer y Derecho Penal. ¿Necesidad de una reforma desde una perspectiva de género?, 2019, p. 116.

${ }^{51}$ Consideran que la circunstancia de género se restringe a las relaciones de pareja hombre-mujer, de acuerdo con la interpretación sistemática de la agravante conforme a la LO 1/2004: MARÍN DE ESPINOSA CEBALLOS, «La agravante genérica de discriminación por razones de género (art. 22.4 CP)», RECPC, (20-27), 2018, pp. 12 ss.; Rueda Martín, RECPC, (21-4), 2019, p. 23; Goyena Huerta, «Artículo 22», en Gómez Tomillo (dir.), Comentarios al Código penal, t. I, 2015, p. 354.

${ }^{52}$ En contra de la compatibilidad en la doctrina: BORJA JIMÉNEZ, «La circunstancia agravante de discriminación del art. 22.4 ${ }^{\mathrm{a}}$, en GonZÁlEz CuSSAC (dir.), Comentarios a la reforma del Código penal de 2015, $2^{\text {a }}$ ed., 2015, p. 122; MuÑoz Conde/García ArÁN, Derecho Penal, PG, $10^{\mathrm{a}}$ ed., 2019, p. 468. A favor: PÉrez Manzano, Revista Jurídica Universidad Autónoma de Madrid, (34), 2016, p. 47; VillacAmPa ESTIARTE, Política criminal española en materia de violencia de género. Valoración crítica, 2018, p. 51; MARÍN DE Espinosa Ceballos, RECPC, (20-27), 2018, pp. 16 s.; Serrano GonzÁlez de Murillo, RP, (44), 2019, pp. 203 ss.
} 
Según la STS 565/2018, de 19 de noviembre: "la primera tiene un matiz netamente subjetivo, basado en consecuencia en la intención -manifestada por actos de violencia-, de llevar a cabo actos de dominación sobre la mujer, mientras que la agravante de parentesco tiene un marcado componente objetivo basado en la convivencia, incluso desconectado de un vínculo afectivo", añadiendo, a diferencia de la STS 420/2018, que esta compatibilidad con la agravante de parentesco en las situaciones de pareja con convivencia "no excluye que la agravante de género del art. 22.4. ${ }^{\mathrm{a}} \mathrm{CP}$ pueda aplicarse también aisladamente si el ataque se hace a una mujer con la que el sujeto activo no tiene ninguna relación de pareja o expareja, pero se pueda desprender de la prueba practicada que se ha realizado el ilícito penal con actos que implican dominación del hombre hacia una mujer por el hecho de ser mujer" (así, por ejemplo, se ha apreciado la agravante de género en relaciones hombre-mujer ajenas a la pareja: SAP de Valencia, sec. 1, $455 / 2019$, de 21 de octubre: tentativa de asesinato contra una hija). Por lo tanto, para la jurisprudencia del TS la agravante de género no acota los sujetos pasivos al ámbito de la pareja, sino que "su ámbito de aplicación extravasa dicha relación de pareja" (STS 99/2019, de 26 de febrero). ${ }^{53}$

Dado que obviamente no todo delito contra una mujer será un delito con el componente de género por el mero hecho de que la víctima sea mujer, será preciso, además, que concurra un fundamento material que explique por qué se agrava la pena en unos casos sí y en otros no. La inserción de esta agravante en el art. 22.4 ${ }^{\mathrm{a}}$ del CP hace que su razón de ser tenga que radicar en la motivación discriminatoria del autor hacia la mujer, pues se incorpora en el ámbito de una circunstancia agravante más amplia de carácter subjetivo que se fundamenta en la motivación del autor, elemento que en todo caso tendrá que ser probado. ${ }^{54}$ Como dice la STS 565/2018, de 19 de noviembre, "es evidente que el fundamento de las agravaciones recogidas en este apartado $4^{\circ}$ reside en el mayor reproche penal que supone que el autor cometa los hechos motivado por sentirse superior a uno de los colectivos que en el mismo se citan y como medio para demostrar además a la víctima que la considera inferior”. También para (la mayor parte de) la doctrina, dice esta sentencia, "la agravante de género prevista en el artículo $22.4^{\circ} \mathrm{CP}$ tiene un fundamento subjetivo, necesitando que concurra en el autor del delito un ánimo de mostrar su superioridad frente a la víctima mujer y demostrarle que ésta es inferior por el mero hecho de serlo. (...) En consecuencia, el fundamento de la agravante se ubica en la mayor reprochabilidad que supone que el autor cometa los hechos contra una mujer por el mero hecho de serlo y en actos que implican, o llevan consigo, actos que evidencian un objetivo y fin de sentirse superior a la misma”. ${ }^{55}$

\footnotetext{
${ }^{53}$ En sentido extensivo de la agravante de género, más allá de la pareja: MAQUEDA ABREU, «El hábito de legislar sin ton ni son. Una lectura feminista de la reforma penal de 2015», Cuadernos de Política Criminal, (118), 2016, pp. 14 s.; SAN Millán FernándeZ, EPC, (39), 2019, p. 343; Alonso ÁlAmo, en Monge FeRnÁNDEZ (dir.), Mujer y Derecho Penal. ¿Necesidad de una reforma desde una perspectiva de género?, 2019, p. 124; Jericó Ojer, en Monge Fernández (dir.), Mujer y Derecho Penal. ¿Necesidad de una reforma desde una perspectiva de género?, 2019, pp. 317 s.

${ }^{54}$ Vid. en este sentido LARRAURI PIJOAN, Criminología crítica y violencia de género, 2018, p. 130, y ACALE SÁNCHEZ, en MARTín SÁNCHEZ (dir.), Estudio Integral de la Violencia de Género: un análisis teórico-práctico desde el Derecho y las Ciencias Sociales, 2018, p. 422 ("la única diferencia entre la aplicación de los tipos neutros con la agravante de discriminación y los tipos sexuados es que en estos últimos el móvil discriminatorio no hay que probarlo especialmente").

${ }^{55}$ Vid. al respecto de la doctrina: BORJA JIMÉNEZ, en GONZÁlEZ CUSSAC (dir.), Comentarios a la reforma del Código penal de 2015, $2^{\text {a }}$ ed., 2015, p. 120; Goyena Huerta, en Gómez Tomillo (dir.), Comentarios al Código penal, t. I, 2015, p. 352; Alastuey Dobón/Escuchuri Aisa, RDP, (23), 2015, p. 58; SANz Mulas, Violencia de género y Pacto de Estado, La huida hacia delante de una norma agotada (LO 1/2004), 2019, pp. 94 ss.; DíEZ
} 
En todo caso deja claro esta línea jurisprudencial que no es la personalidad del sujeto lo que justifica por sí misma la aplicación de la agravante, ni tampoco -como dice la doctrina- una motivación misógina de odio hacia las mujeres, ${ }^{56}$ sino su intención, actitud o situación de dominación y desprecio sobre la mujer (STS 420/2018, de 25 de septiembre), una situación de dominación, subordinación o sumisión por parte de la víctima como móvil determinante de la acción del autor (STS 584/2018, de 23 de noviembre) o una relación de dominación (STS $707 / 2018$, de 15 de enero de 2019), puestas de manifiesto a través de los hechos probados que circunstancian la correspondiente actuación. Pese a las reticencias de un sector de la doctrina que rechaza la motivación por sus dificultades de prueba y que se inclina por fundamentaciones objetivas en el ámbito de lo injusto, la inferencia de la motivación discriminatoria por el género no presenta tantas dificultades en la práctica como se pretende sugerir, o no muchas más que la de otros elementos subjetivos como el dolo, a la vista de las numerosas sentencias que constatan la concurrencia en el autor de aquella motivación a partir de determinados elementos fácticos que han de hacerse constar en la relación de hechos probados. Pueden ser demostrativos de la motivación discriminatoria de género, como resalta RUEDA MARTín, insultos, vejaciones o humillaciones que pueden no constituir un ilícito penal independiente, pero que se desarrollan coetáneamente al hecho delictivo, así como también actividades o situaciones anteriores al hecho delictivo que son indicativas de las relaciones precedentes entre el autor y la víctima. ${ }^{57}$

Sin embargo, no parece fácil conciliar la naturaleza subjetiva de la circunstancia de género con la interpretación objetivista de los tipos de violencia de género. ¿Cómo puede insertarse esta circunstancia en nuestro $\mathrm{CP}$ en vista de la existencia de delitos de violencia de género en la

RIPOLlÉs, $P G, 4^{\text {a }}$ ed., pp. 503 s. (agrava la culpabilidad), MIR PUIG, $P G, 10^{\text {a }}$ ed., 2015, p. 565 (agrava lo injusto subjetivo); ACALE SÁNCHEZ, en MARTín SÁNCHEZ (dir.), Estudio Integral de la Violencia de Género: un análisis teórico-práctico desde el Derecho y las Ciencias Sociales, 2018, pp. 420, 423 (mayor desvalor de la acción); RUEDA MARTín, RECPC, (21-4), 2019, p. 12 (agrava el desvalor de la acción y la culpabilidad). Por su parte, considerando que la agravante incrementa el desvalor del resultado, que residiría, según unos en el ataque a la igualdad real, según otros en la vulneración del derecho a no ser discriminado, vid. Alonso Álamo, en Monge FernÁndeZ (dir.), Mujer y Derecho Penal. ¿Necesidad de una reforma desde una perspectiva de género?, 2019, pp. 107 ss. (que postula de lege ferenda la modificación de la circunstancia para eliminar la motivación, pero exigiendo un contexto de objetiva dominación y sometimiento abarcado por el conocimiento del autor, p. 121; con ello se desmarca de su posición personal sobre la circunstancia de "motivos discriminatorios", antes de la incorporación del género, puesta de relieve en AlONSo ÁLAMO, «La circunstancia agravante de discriminación», en La ciencia del Derecho Penal ante el nuevo siglo. Libro homenaje al Profesor Doctor Don José Cerezo Mir, Tecnos, 2002, pp. 334 ss.); LAURENZo Copello, «La discriminación en el Código penal de1995», Estudios Penales y Criminológicos, (19), 1996, p. 258, ReBOLLO VARGAS, «La agravante de discriminación por razón de sexo y su fundamento (art. 22.4 del Código Penal)», 2015, p. 25, y SAn Millán FernándeZ, Estudios Penales y Criminológicos, (39), 2019, pp. 334 ss. (según esta autora, aunque la fundamentación de la circunstancia sea objetiva, no es de aplicación automática, sino que será preciso constatar que, en el caso concreto, la actuación del hombre constituye una discriminación del hombre hacia la mujer por su género, por lo que será comunicable). Próxima a éstas se encuentra la propuesta de interpretación "objetivadora” de la agravante que mantiene DopICo GómEZAller, «Motivos racistas o similares» en Memento Práctico Penal, Francis Lefebvre, 2019, p. 505 (para el supuesto de agresiones sexistas considera preferible una interpretación "restrictiva” que, a su juicio, se produciría prescindiendo de la prueba de la motivación y atendiendo exclusivamente a que "las agresiones sexistas dolosamente busquen perpetuar la idea de dominación masculina y discriminación”).

${ }^{56}$ MAQUEDA ABREU, «¿Necesitan un móvil discriminatorio las agravantes de sexo/género del art. 22.4 CP?», en Estudios de Derecho penal, Homenaje al profesor Santiago Mir Puig, 2017, p. 708; RuEDA MARTÍN, RECPC, (21-4), 2019, pp. 8 s.; Alonso Álamo, en Monge FernándeZ (dir.), Mujer y Derecho Penal. ¿Necesidad de una reforma desde una perspectiva de género?, 2019, pp. $119 \mathrm{~s}$.

${ }^{57}$ RUEDA MARTín, RECPC, (21-4), 2019, pp. 29 s. 
pareja en los que, según la reciente jurisprudencia del TS, resulta irrelevante no solo la motivación del autor, sino incluso la existencia de una situación de dominación? ¿Afecta la interpretación de esos delitos a la agravante de género con relación a aquellos hechos delictivos comunes que sean cometidos en el marco de la pareja por parte del varón contra la mujer? ¿Es posible mantener dos interpretaciones de la agravante según se aplique a parejas o no?

La STS 99/2019, de 26 de febrero, ${ }^{58}$ pretende dar respuesta a las cuestiones acabadas de formular señalando que la STS 677/2018 ha considerado respecto del delito del art. 153.1 CP que la exigencia de un elemento subjetivo supone exacerbar la verdadera intención del legislador, por lo que coherentemente para la apreciación de la circunstancia en las relaciones de pareja bastará el presupuesto objetivo de una específica relación varón-autor y mujervíctima. Es decir, en la medida en que la interpretación de la previsión legal ha de enmarcarse en un objetivo corrector de la desigualdad o discriminación ocurrida en un ámbito de relación autor-víctima, la misma objetividad con que se aprecian los tipos de violencia de género debe presidir también, al compartir fundamento, la aplicación de la agravante de género. Ello supone prescindir de la intencionalidad y, en definitiva, del elemento subjetivo, pero también de otro de carácter objetivo, esto es, la existencia de una situación o contexto de dominación o discriminación en las relaciones de pareja, por cuanto en ellas la discriminación presenta un carácter estructural, pero dicho dato no tiene por qué concurrir en las relaciones hombre-mujer fuera de aquel ámbito relacional. Tanto es así que, para aplicar la agravante en casos ajenos a esa relación de pareja, prosigue la sentencia, "habrá de exigirse al menos una asimetría en la relación entre varón-autor y mujer-víctima que sea reflejo de la discriminación que constituye el fundamento de la mayor sanción penal". Por el contrario, en las relaciones de pareja es suficiente con que "el hecho probado dé cuenta de la relación típica de la circunstancia agravatoria, de tal manera que el delito se entienda como manifestación objetiva de la discriminación característica”. En suma, dos formas de interpretar una misma circunstancia, según se aplique a parejas o no, lo que no parece aceptable respecto a una misma circunstancia de género, y menos aún en el contexto de la agravante de motivos discriminatorios de carácter general. Y ello sobre todo en la medida en que en los hechos cometidos en el ámbito de las relaciones de pareja constitutivos de un delito común generalmente concurrirá también la agravante de parentesco, y, en consecuencia, no será preciso mantener esa diferente interpretación de la agravante de género, según que el delito se haya producido en el ámbito relacional de la pareja (delito común con las posibles agravantes de parentesco y género) o no (delito común con la posible agravante de género). Por otro lado, si llevamos hasta el final esta posición jurisprudencial tendremos que afirmar que cualquier delito común -incluso un tipo privilegiado- que el hombre cometa contra su pareja o expareja femenina queda automáticamente agravado mediante la circunstancia de género con tal que la acusación la invoque en la calificación de los hechos.

Hasta el momento no se puede decir que se encuentre consolidado un determinado criterio del TS sobre la agravante de género. Las SsTS 223/2019, de 29 de abril y 351/2019, de 19 de julio siguen aludiendo para apreciarla a los motivos o a la motivación del autor en supuestos de asesinatos a parejas o exparejas. La STS 452/2019, de 8 de octubre, se acoge al criterio marcado por la n. ${ }^{\circ}$ 99/2019 y considera que la norma no exige que el autor muestre voluntad de dominar o discriminar, basta con que el delito evidencie una relación machista. También la STS 448/2019, de 9 de octubre, se inclina por adoptar dicho criterio para interpretar la agravante de

${ }^{58}$ Vid. el comentario a dicha sentencia de CADENA SERRANO, "Aplicación de la circunstancia atenuante de actuar por razones de género», La Ley Digital, (8669), 2019, pp. 1 ss. 
discriminación por motivos ideológicos: "que el delito se entienda como manifestación objetiva de la discriminación característica”. De manera, por ejemplo, que el hecho probado señale cuál es la ideología de la víctima que el sujeto rechaza y sobre la que se apoya como móvil, para realización de la conducta. En suma, es ciertamente aún confusa la jurisprudencia, pero es clara su tendencia hacia la eliminación o reducción de las pruebas de carácter subjetivo en general, y en el ámbito de la violencia de género en particular. El móvil, si se presenta, es mero reflejo de un dato objetivo u objetivable que se estima prueba suficiente.

A este maremágnum jurisprudencial se une la deficiente técnica jurídica de la regulación legal que, como se ha puesto de manifiesto, es asistemática, ya que las distintas reformas obedecen a idearios y finalidades diversas, y tanto los tipos cualificados como las respectivas circunstancias del delito no presentan la debida coherencia ni armonía que sea capaz de impedir la generación de duplicidades y los problemas de solapamientos entre las circunstancias agravantes (parentesco, género, incluso abuso de superioridad). ${ }^{59}$ Pues bien, lejos de buscar la coherencia del sistema, al legislador solo le preocupa aspirar a introducir nuevas reformas legales de carácter penal que, aún sin tiempo para digerir las anteriores, se presentan como la panacea contra la violencia de género sin que lo vayan a ser realmente.

\section{Los trabajos preliminares para alcanzar un Pacto de Estado en materia de violencia de género: aspectos de Derecho Penal sustantivo}

La nueva doctrina del TS sobre los tipos de violencia de género y sobre la agravante de género se conecta, por lo que a ideario político-criminal respecta, con las políticas punitivistas y expansivas que anuncia el Pacto de Estado contra la violencia de género. En él se apuesta por recurrir una vez más Derecho penal, en algunos casos para cumplir con las obligaciones derivadas de la normativa internacional, pero en otros solo para intensificar el fuerte simbolismo que emana de la regulación de género.

Partiendo del reconocimiento de que la violencia de género es uno de los principales problemas que sufre nuestro país y de la necesidad de recuperar el consenso de la LO 1/2004, el Congreso de los Diputados aprobó por unanimidad una Proposición no de Ley, con fecha 15 de noviembre de 2016 (núm. expte. 162/000004 y 162/000135, puesto que se acumulaban dos proposiciones no de ley de los Grupos parlamentarios popular y socialista), en la que se instaba al Gobierno a suscribir un Pacto de Estado en materia de violencia de género junto con las Comunidades Autónomas y la Federación Española de Municipios y Provincias. A tal fin se estableció la creación en el seno de la Comisión de Igualdad del Congreso de una Subcomisión para elaborar un informe con la finalidad de analizar los problemas que presenta la LO $1 / 2004$, atender a las recomendaciones de los organismos internacionales y efectuar propuestas de actuación que incluyeran reformas legales, para lo cual ante dicha Subcomisión comparecieron 66 personas expertas.

Paralelamente, la Comisión de Igualdad del Senado decidió, el 21 de diciembre de 2016, la creación de una Ponencia de estudio para elaborar estrategias contra la violencia de género, y en ella comparecieron un total de 52 expertas y expertos en las muy diversas materias que se insertan en la LO 1/2004, asistenciales, educativas, psicológicas, médicas, procesales, penales, policiales, etc., tanto de ámbitos institucionales como asociativos. Algunos comparecientes, también del ámbito universitario, se pronunciaron en varias ocasiones sobre cuestiones

\footnotetext{
${ }^{59}$ SerRano GonZÁlez de Murillo, RP, (44), 2019, pp. 202 s.
} 
estrictamente penales, efectuando propuestas de ampliación o creación de nuevas tipologías delictivas y/o de sus respectivas respuestas penales. Sin embargo, llama la atención la práctica total ausencia de penalistas del ámbito universitario que pudieran aportar una visión desde la ciencia o desde la dogmática del Derecho Penal. ${ }^{60 / 61}$

Entre las cuestiones penales, planteadas en el seno de ambas subcomisiones del Congreso y del Senado, una de ellas versaba sobre la necesidad de eliminar la exigencia de elementos subjetivos para apreciar los tipos de violencia de género, algo que finalmente no fue recogido en el Documento refundido de medidas del Pacto de Estado en materia de violencia de género, de 13 de mayo de 2019, posiblemente porque la jurisprudencia del TS ya se había encargado de dicha cuestión. El ponente de la STS 677/2018, Vicente Magro Servet, fue uno de los que propuso la supresión del elemento subjetivo. Dicha propuesta fue incluida con el n. ${ }^{\circ} 242$ en el informe del Senado bajo el título "supresión del elemento subjetivo para la apreciación del delito", y en ella se sugería incorporar a los artículos pertinentes del Código penal la redacción "con cualquier fin" o "con independencia del fin perseguido", coincidiendo esta propuesta con la del documento de estudio del CGPJ del año 2016 sobre la aplicación de la LO 1/2004, que se expresaba en el mismo sentido. ${ }^{62}$ Con ello se habrían solventado las cuestiones de carácter subjetivo relacionadas con los tipos de violencia de género, dejando en cambio sin respuesta las de carácter objetivo (si debería exigirse en el caso concreto la existencia de una posición de dominio, poder o desigualdad). Aunque finalmente el Pacto de Estado prescindió de esta propuesta legislativa por resultar innecesaria, dada la posición interpretativa últimamente adoptada por el TS, conviene repasar alguno de los argumentos de quienes rechazaban que fuera exigible la intención subjetiva de subyugar o someter a la mujer para que exista una condena por violencia de género: "consideran fundamental que no sea necesario indagar si el agresor pretendía establecer una relación de poder sobre la mujer” 63 "porque dificulta

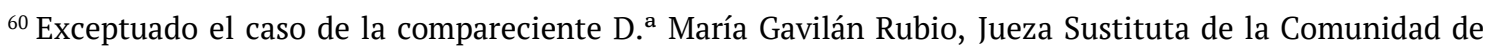
Madrid y Profesora de Derecho Penal y Procesal Penal en el Real Centro Universitario María Cristina, a quien concretamente se deben las propuestas de reformar el art. 21.4 CP para suprimir la atenuante de confesión en los delitos de violencia de género, así como la de modificar los arts. 48 (para que pueda suspenderse la custodia compartida cuando se esté tramitando un proceso de violencia de género en el que se haya dictado orden de protección) y 187.1 (para tipificar el proxenetismo en todas sus formas).

${ }^{61}$ Lo que, como señala Villacampa Estiarte, Política criminal española en materia de violencia de género. Valoración crítica, 2018, p. 229, agranda todavía más “la brecha existente entre lo que la academia preconiza, con base en resultados obtenidos empleando metodología científica, y lo que la clase política, seguramente con el objetivo último de extraer el correspondiente rédito electoral, se propone hacer”.

${ }^{62}$ Estudio sobre la aplicación de la Ley integral contra la violencia de género por las Audiencias Provinciales (publicado en marzo de 2016 y accesible desde la web del Poder Judicial: www.poderjudicial.es), entre cuyas conclusiones figuraba la no exigencia del elemento intencional de dominación o machismo en la conducta del autor. Se recordaba la existencia de una clara división interpretativa en este tema, decantándose por la no exigencia de esa prueba, sino solo del hecho de golpear o maltratar. Urgía por ello la reforma de los tipos penales de violencia de género para añadir la expresión "el que con cualquier intención” (pp. 203 s.).

${ }^{63}$ Comparecencia en el Congreso de Filomena Peláez Solís (Presidenta del Consejo General de la Abogacía Española), obrante en el documento de Aprobación por el Pleno del Congreso de los Diputados del Informe de la Subcomisión creada en el seno de la Comisión de Igualdad para un Pacto de Estado en materia de violencia de género (en adelante Informe de la Subcomisión), p. 49; la misma sugerencia de eliminación del elemento subjetivo - "afán de dominación"- y, por consiguiente "extender el elemento objetivo a todos los tipos delictivos de violencia de género” formuló en su Comparecencia en el Senado, obrante en el documento "Informe de la ponencia de estudio para la elaboración de estrategias contra la violencia de género”, aprobado por la Comisión de igualdad del Senado, en su sesión de 28 de julio de 2017, p. 15. En igual sentido la comparecencia en el Congreso de Paloma Marín López (Magistrada, ex Secretaria Técnica del Observatorio contra la violencia doméstica y de género del CGPJ), proponiendo la adición a los tipos
} 
extraordinariamente que se produzca una condena" ${ }^{64}$ o constituye una probatio diabólica. ${ }^{65} \mathrm{Sin}$ embargo, por un lado, la condena está prácticamente garantizada en la medida en que, a falta de un elemento (objetivo o) subjetivo que cualifica la infracción, el hecho no queda impune, sino que entra en aplicación el tipo básico y subsidiario ${ }^{66} \mathrm{y}$, por otro lado, las dificultades probatorias no tendrían que servir como excusa para renunciar a la prueba y, en consecuencia, a la evidencia de que con ese acto se reproduce "sin la menor duda" una pauta patriarcal o machista. El problema es que esta prueba es mucho más difícil de lograr en un maltrato de obra leve y ocasional que en un asesinato. Por otro lado, la eliminación de toda referencia subjetiva en los tipos de género contrasta con la recomendación del Pacto de aplicar la circunstancia cuarta del art. 22 del Código penal "en todos los casos en el que resulte probado el elemento subjetivo de motivos machistas o discriminatorios hacia la mujer, o por razones de género, en los casos de agresión sexual y abuso sexual" ${ }^{67}$ Tanto en éstos como en todos los delitos en los que se proponga la circunstancia de razones de género es difícil prescindir de la motivación como elemento que sustenta la agravación. ${ }^{68}$

Un segundo aspecto destacable de las comparecencias en el seno de las Subcomisiones del Congreso y del Senado fue la recurrente deturpación del concepto de violencia, al ampliarse hasta extremos sinuosos que resultan incompatibles con su concepto jurídico-penal o que lo desbordan. Se afirmó, en primer lugar, que "el término violencia implica conductas que rebasan el nivel de lo aceptable", hasta el punto de poner de manifiesto que se debate si en el "micromachismo" hay violencia. ${ }^{69}$ Se emplearon numerosas variantes adjetivas de la violencia. Así, la expresión "violencia virtual" se utilizó para referirse a comportamientos violentos entre menores y adolescentes agravados por el uso de nuevas tecnologías, ${ }^{70} \mathrm{y}$ la de "violencia de género digital" para aludir a la "sextorsión" o a la "pornovenganza” y al control de las

penales concernidos (esto es, las manifestaciones más leves de la violencia de género) del inciso “con cualquier fin”, obrante en el Informe de la Subcomisión, p. 53.

${ }^{64}$ Comparecencia en el Congreso de Ángeles Carmona Vergara (Presidenta del Observatorio contra la violencia doméstica y de género del Consejo General del Poder Judicial), obrante en el Informe de la Subcomisión, p. 25; la misma sugerencia de supresión del elemento subjetivo - “afán de dominación”- en todos los tipos delictivos relacionados con la violencia de género efectuó en su Comparecencia en el Senado, obrante en el documento "Informe de la ponencia de estudio para la elaboración de estrategias contra la violencia de género”, p. 11.

${ }^{65}$ Comparecencia en el Senado de Mercé Claramunt Bielsa (Abogada especialista en violencia de género), obrante en el documento "Informe de la ponencia de estudio para la elaboración de estrategias contra la violencia de género”, p. 20.

${ }^{66}$ Teóricamente en el caso del art. 153.1, la función de tipo básico o subsidiario la desempeña el art. 153.2, ambos perseguibles de oficio. Otra cuestión es que el tenor literal de ambos preceptos se encuentra redactado en modo de exclusión recíproca (por lo que, aparentemente, de no apreciarse el tipo del art. 153.1, el hombre respondería tan solo de un delito leve -art. 147.2 y 3- perseguible mediante denuncia), si bien, el voto particular de la STS 677/2018 considera que no es la única interpretación posible y que el art. 153.2 sería aplicable a ambos integrantes de la pareja, cualquiera que fuera su sexo.

${ }^{67}$ Propuesta de actuación n. ${ }^{\circ} 92$ del Informe de la Subcomisión del Congreso.

${ }^{68}$ A favor incluso de introducir expresamente en los tipos de violencia de género el elemento anímico de la discriminación como presupuesto de los mismos, SANZ MulaS, Violencia de género y Pacto de Estado, La huida hacia delante de una norma agotada (LO 1/2004), 2019, p. 98

${ }^{69}$ Comparecencia en el Congreso de Begoña Marugán Pintos (Adjunta a la Secretaría de la Mujer de la Federación de Servicios de CCOO, Doctora en Sociología y Licenciada en Ciencias Políticas y Sociología), obrante en el Informe de la Subcomisión, pp. $101 \mathrm{~s}$.

${ }^{70}$ Comparecencia en el Congreso de Joaquín Pérez de la Peña (Jefe de la Unidad de coordinación contra la violencia sobre la mujer de la Delegación del Gobierno en Andalucía), obrante en el Informe de la Subcomisión, p. 59. 
adolescentes en las redes sociales por parte de sus parejas o exparejas; $;^{71} \sin$ embargo, al margen de que la denominada "ciberdelincuencia de género" constituya en el futuro un tipo penal independiente, ${ }^{72}$ el carácter violento de tales conductas es dudoso o forzado. Otra variante de dudosa naturaleza penal fue la de "violencia corporal" en el ámbito laboral, subyacente al hecho de exigir a la mujer vestir de una determinada manera. ${ }^{73}$ No menos elocuente con relación a los delitos sexuales resulta la locución "violencia expresiva", en el sentido de que "el violador en realidad se dirige a otros hombres en una especie de rito que tiende a demostrar su masculinidad", ${ }^{74}$ y ello al margen o como añadido de la violencia que es inherente al hecho mismo de la violación. También se solicitó que el síndrome de alienación parental ${ }^{75} \mathrm{y}$ la querulancia se reconocieran como formas de violencia contra la mujer, ${ }^{76} \mathrm{si}$ bien las violencias psicológicas resultan punibles por sí mismas, pudiendo presentarse aquéllas como formas concretas de manifestación.

Tales referencias a la violencia de género, a veces en formas sutiles y muy diversas, guardan relación con una ampliación progresiva del concepto de violencia de género en las convenciones internacionales. La definición de violencia contra la mujer contenida en el art. 3 a) del Convenio de Estambul como violación de los derechos humanos y una forma de discriminación contra las mujeres designa "todos los actos de violencia basados en el género que implican o pueden implicar para las mujeres daños o sufrimientos de naturaleza física, sexual, psicológica o económica, incluidas las amenazas de realizar dichos actos, la coacción o la privación arbitraria de libertad, en la vida pública o privada" ${ }^{77} \mathrm{Al}$ margen del hecho nada irrelevante de que el texto internacional no reduce la violencia contra la mujer a la que se ejerce dentro de la pareja, sino que la extiende a las violencias que tengan lugar en las relaciones hombre-mujer en comunidad en general, de acuerdo con esta definición es posible comprender como violencia de género en sentido amplio un conjunto de conductas delictivas que, aunque puedan, por ejemplo, causar sufrimientos psicológicos a las víctimas, no constituyen en nuestro Código penal un tipo que podamos denominar, ni siquiera en sentido amplio, de "violencia de género", sino un delito contra la intimidad o contra las relaciones familiares, con independencia de que al mismo pueda corresponderle una circunstancia agravante de género. En el citado convenio se limitan las formas delictivas que los Estados Parte se comprometen a tipificar, a saber, violencia psicológica, acoso, violencia física,

\footnotetext{
${ }^{71}$ Comparecencia en el Congreso de Jorge Flores Fernández (Fundador y Director de Pantallas Amigas), obrante en el Informe de la Subcomisión, pp. $114 \mathrm{~s}$.

${ }^{72}$ Comparecencia en el Congreso de María José Ordóñez Carbajal (Delegada del Gobierno para la violencia de género), obrante en el Informe de la Subcomisión, p. 206.

${ }^{73}$ Comparecencia en el Congreso de Carla Millán Peñaranda (Responsable de derechos e igualdad de oportunidades del Consejo de la Juventud de España), obrante en el Informe de la Subcomisión, p. 75.

${ }^{74}$ Comparecencia en el Congreso de Justa Montero Corominas (Miembro de la Asamblea Feminista de Madrid), obrante en el Informe de la Subcomisión, p. 144.

${ }^{75}$ En sus siglas "SAP" hace referencia al estado psicológico de un niño en contra de un familiar o progenitor influido por otro familiar o progenitor.

${ }^{76}$ Comparecencia en el Congreso de Gloria Vázquez Portas (Presidenta de la Asociación Ve-La luz), obrante en el Informe de la Subcomisión, p. 109.

${ }^{77}$ Prácticamente esta definición es similar a la que figura en la Declaración sobre la eliminación de la violencia contra la mujer, contenida en la Resolución 48/104, de 20 de diciembre de 1993, de la Asamblea General de Naciones Unidas (por "violencia contra la mujer" se entiende todo acto de violencia basado en la pertenencia al sexo femenino que tenga o pueda tener como resultado un daño o sufrimiento físico, sexual o psicológico para la mujer, así como las amenazas de tales actos, la coacción o la privación arbitraria de la libertad, tanto si se producen en la vida pública como en la vida privada). Únicamente, aunque no es poco, el Convenio de Estambul añade que los daños o sufrimientos derivados de la violencia pueden ser también de carácter económico.
} 
violencia sexual, matrimonios forzosos, mutilaciones genitales femeninas, aborto y esterilización forzosos y acoso sexual. Es decir, no se incorporan al convenio otros hechos delictivos que se encuentran tipificados en nuestra legislación penal como delitos comunes, aunque puedan suponer a las mujeres que sean víctima de los mismos daños o sufrimientos de naturaleza psicológica o económica que las “violentan”. No obstante, con base en la definición contenida en el convenio, se proclamaron por alguno de los expertos que comparecieron en el Parlamento como formas de violencia o de perpetuar la violencia contra las mujeres conductas tales como el impago de pensiones e hipotecas, ${ }^{78}$ proponiendo, en consecuencia, que el impago de pensiones (o, con la misma coherencia, el alzamiento de bienes) se reconozca como delito de violencia de género de carácter económico. ${ }^{79}$

También desde el punto de vista demoscópico se observa una utilización más que extensiva del concepto de violencia contra la mujer, en la medida en que alguna de las conductas que se incardinan dentro del ámbito de estudio no se corresponden, aun cuando representen conductas machistas, ni con violencia de género, ni con otra clase de delito -aunque sea levecontra las personas. Y así, por ejemplo, si atendemos a la Macroencuesta de violencia contra la mujer de 2015, de la misma se puede colegir que aproximadamente una de cada diez mujeres residentes en España de 16 y más años ha sufrido violencia física o sexual por parte de alguna pareja o expareja en algún momento de su vida (pp. 29 y 246). De lo que ya no se puede estar tan seguro es de que se esté aludiendo en todo caso a comportamientos con relevancia jurídicopenal, tanto en lo que respecta a la violencia sexual como también a otra clase de violencias, pues algunas de las que así se califican -y sin más aditamentos- consisten en simples comportamientos machistas éticamente reprobables pero no punibles, ya que está ausente la propia “violencia” contra la persona o la "amenaza” de la misma. ${ }^{80}$

De la exacerbación conceptual de la violencia de género se pasa a la exageración cuando se equipara la violencia de género con el terrorismo, como ocurrió entre algunos comparecientes. Es decir, pasamos de que incluso hechos nimios o de muy escasa relevancia producidos en el ámbito de la pareja puedan llegar a ser constitutivos de violencia de género a que toda violencia de género sea terrorismo, y ni lo uno ni lo otro resulta congruente desde un punto de vista jurídico-penal. Aun cuando por parte de algunos expertos se mencionó únicamente la necesidad de proporcionar a las víctimas de violencia de género las ayudas que reciben las

\footnotetext{
${ }^{78}$ Comparecencia en el Congreso de Susana Martínez Novo (Presidenta de la Comisión para la investigación de malos tratos a mujeres), obrante en el Informe de la Subcomisión, p. 129.

${ }^{79}$ Comparecencia en el Congreso de Filomena Peláez Solís (Presidenta del Consejo General de la Abogacía Española), obrante en el Informe de la Subcomisión, p. 49.

${ }^{80}$ Existe machismo pero no violencia: por lo que respecta a la denominada "violencia sexual", en el hecho de mantener relaciones sexuales con la pareja sin desearlo por miedo a la reacción de la pareja, o la práctica de relaciones sexuales que la mujer encuentra humillante o degradante; en supuestos que se clasifican como "violencia psicológica del control", en el hecho de ignorar a la persona o tratarla con indiferencia, enfadarse si la pareja femenina habla con terceros o sospechar infundadamente de una infidelidad; en cuanto a la "violencia psicológica emocional", en conductas como hacer sentir mal a una persona consigo misma, asustar a propósito, por ejemplo, gritando, rompiendo cosas o mirándole de determinada forma; y, por último en la "violencia económica", relativa a negarse a dar dinero para gastos del hogar o no dejar trabajar o estudiar fuera de casa. Es frecuente, como se observa, que el hecho descriptor del machismo se conciba en estos estudios demoscópicos desde el punto de vista de la comprensión de la víctima, y no tanto como descriptivo del comportamiento del autor y menos aún de la violencia que comporta. Y ello se entiende porque esos estudios no parten ni son representativos de las conductas con relevancia penal. Pero desde ese punto de vista se envía un mensaje a la sociedad que acrecienta la imagen de la violencia contra la mujer, cuando son ante todo conductas machistas desprovistas de significación penal.
} 
víctimas del terrorismo, otros afirmaron que la violencia de género es una forma de terrorismo. Así, por ejemplo, se empleó la expresión "terrorismo machista" como algo que debe ser considerado cuestión de Estado, ${ }^{81} \mathrm{o}$ se efectuó un paralelismo conceptual destacando sus elementos comunes. ${ }^{82}$ Se calificó la violencia machista como un tipo más de terrorismo con el argumento de que ha causado más muertes que el terrorismo de ETA, hasta el punto de estimarla, en una nueva confusión conceptual, un "terrorismo de Estado", de modo que así puedan las víctimas acceder a los mismos beneficios que las víctimas del terrorismo de ETA. ${ }^{83}$ Aunque lo verdaderamente chocante es que el exceso verbal en el que se incurre, calificando como terrorismo la violencia de género, sea aplaudido desde la más alta magistratura. ${ }^{84}$

Mención aparte merece la cuestión de la prostitución, pues puede ser contemplada desde el punto de vista de la violencia sexual con un claro componente de género cuando la víctima es una mujer; incluso está directamente asociada con el delito de trata de seres humanos con fines de explotación sexual. Más allá del proxenetismo y de su persecución, aunque no sea coactivo y sí lucrativo, el consumo sexual de mujeres se presenta o visualiza como una forma de violencia, según algunos expertos. ${ }^{85}$ Sin embargo, en el Pacto de Estado contra la violencia de género la prohibición de la prostitución no se aborda. La única propuesta que se efectúa al respecto consiste en desincentivar la demanda de la prostitución mediante campañas de concienciación y talleres de sensibilización dirigidos a los jóvenes (propuesta n. ${ }^{\circ} 265$ del Pacto).

\section{El Pacto de Estado en materia de violencia de género (texto refundido de 13 de mayo de 2019): las propuestas penales de reforma}

Los trabajos de las Subcomisiones de Igualdad en el Congreso y el Senado se nutrieron también de las aportaciones de Comisión General de las Comunidades Autónomas en el Senado (aprobadas en moción n. ${ }^{\circ} 51$ del Pleno del Senado, de 5 de abril de 2017) y del Observatorio Estatal de violencia contra la mujer (a través de un Grupo de trabajo que contó con la participación de las CCAA y de organizaciones especializadas de la sociedad civil, sumando 46 entidades participantes). Finalmente, el 13 de septiembre de 2017, el Pleno del Senado aprobó, por unanimidad, el Informe de la Ponencia de Estudio para la elaboración de estrategias contra la violencia de género, mientras que el 28 de septiembre de 2017 se aprobó en el Congreso sin votos en contra el Informe de la Subcomisión para un Pacto de Estado en materia de violencia de género. En ambos textos, remitidos al Gobierno, se incorporan un conjunto de propuestas de actuación para los próximos años (214 medidas en el caso del Congreso y 267 en el caso del

\footnotetext{
${ }^{81}$ Comparecencia en el Congreso de Begoña San José Serrán (Miembro de la Plataforma 7-N contra las violencias machistas), obrante en el Informe de la Subcomisión, p. 95.

${ }^{82}$ Comparecencia en el Congreso de José María Fernández Calleja (Profesor de Periodismo de la Universidad Carlos III de Madrid, Licenciado en Historia por la Universidad de Valladolid, Doctor en Ciencias de la Información por la Universidad Complutense de Madrid), obrante en el Informe de la Subcomisión, pp. $120 \mathrm{~s}$.

${ }^{83}$ Comparecencia en el Congreso de Estela Sánchez Benítez (Vicepresidenta segunda del Consejo Andaluz de Participación de las Mujeres, CAPM), obrante en el Informe de la Subcomisión, p. 155. Semejante paralelismo se observó en la comparecencia de Amalia Fernández Doyague (Presidenta de la Asociación de Juristas THEMIS), p. 174, comparando el número de víctimas del terrorismo de ETA (20 anuales) con las del "terrorismo machista" (60/63 anuales).

${ }^{84}$ MAgro Servet, Prólogo al Memento experto Violencia Machista, La Ley Digital, Francis Lefebvre, 2019, p. 9, considera un acierto la denominación terrorismo de género.

${ }^{85}$ Comparecencia en el Congreso de Rosario Carracedo Burillo (Portavoz de la Plataforma Estatal de Organizaciones de Mujeres por la Abolición de la Prostitución), obrante en el Informe de la Subcomisión, p. 141.
} 
Senado) a partir de las cuales se desarrolla el denominado "Pacto de Estado contra la violencia de género", cuya ratificación por parte de Grupos Parlamentarios, CCAA y entidades locales tuvo lugar en diciembre de 2017.

Pues bien, en el Documento refundido, de 13 de mayo de 2019, del citado Pacto de Estado, dentro del Eje 2, sobre mejora de la respuesta institucional, en su punto 2.6, relativo a justicia, se incorporan algunas medidas en materia penal, de las cuales solo seleccionamos a continuación para comentar sucintamente las que se refieren a la materia penal sustantiva tanto desde la perspectiva de las tipologías delictivas como de las circunstancias modificativas de la responsabilidad:

a) La n. ${ }^{\circ} 102$ consiste en "ampliar el concepto de violencia de género a todos los tipos de violencia contra las mujeres contenidos en el Convenio de Estambul". Esto implica, en primer lugar, que la violencia de género no se limite a la derivada de las relaciones de pareja, sino que comprenda también la realizada fuera de ese ámbito y, por tanto, en cualquier esfera social o comunitaria, pero siempre que la violencia tenga lugar por la condición femenina de la víctima (violencia contra la mujer porque es una mujer). En segundo lugar, debe distinguirse entre el concepto de "violencia contra las mujeres" y el de "violencia de género", ya que aquél, según el Convenio de Estambul, comprende no solo la "violencia física y psicológica, incluidas las agresiones a la libertad sexual, las amenazas, las coacciones o la privación arbitraria de libertad" (manifestaciones de la violencia contra las mujeres ya reconocidas como violencia de género por el art. 1.3 LO 1/2004), sino también "los actos de violencia basados en el género que impliquen o puedan implicar para las mujeres daños o sufrimientos de naturaleza (...) económica" (art. 3.a del Convenio de Estambul). Por otro lado, se acotan en el Convenio de Estambul como hechos que deben ser tipificados por los Estados parte toda una serie de delitos que no necesariamente vienen definidos por el género del sujeto pasivo, pues salvo en dos de ellos -la mutilación genital femenina (art. 38) y el aborto y esterilización forzosos (art. 39)-, aquél se caracteriza en el resto de tipologías delictivas de modo neutral como "persona", lo que hace pensar que si se designan éstos, y no otros especialmente, es porque afectan a las mujeres de manera desproporcionada. Tras la reforma del CP de 2015 prácticamente todos esos delitos se encuentran ya reconocidos como figuras delictivas en nuestro ordenamiento jurídico, constituyan o no tipos o delitos de violencia de género, y por ello sin perjuicio en este último caso de la aplicación de la agravante de género, circunstancia que realmente permite configurar esos delitos de violencia contra la mujer (que no constituyen tipos de violencia de género conforme a la LO 1/2004) como "violencia contra la mujer por razones de género". ${ }^{86}$

\footnotetext{
${ }^{86}$ Se trata de los siguientes comportamientos (el texto entrecomillado como descriptor de cada uno de ellos no responde a la literalidad del precepto, aunque sí a su contenido):

aa) violencia psicológica (art. 33, "hecho intencionado de atentar gravemente contra la integridad psicológica de una persona mediante amenazas y coacciones", lo cual excede las coacciones y amenazas leves de género en la pareja de nuestro $\mathrm{CP}$, aunque también se encuentran penadas sin la perspectiva de género en otros tipos);

ab) acoso (art. 34, "hecho intencionado de adoptar, en varias ocasiones, un comportamiento amenazador contra otra persona que lleve a ésta a temer por su seguridad", que ha inspirado la tipificación como delito común del acoso persecutorio del art. 172 ter CP en 2015, aunque el contenido del delito descrito en el convenio conforma una perspectiva mucho más subjetiva del mismo al enfocarse en el punto de vista de la víctima);

ac) violencia física (art. 35, "hecho intencionado de cometer actos de violencia física sobre otra persona", el cual puede encuadrarse en distintos tipos de nuestro $\mathrm{CP}$, unos de género y otros comunes);
} 
Al margen de ello, otras medidas previstas en el Pacto incluyen la modificación o ampliación de ciertos delitos concretos pero comunes. En particular, se propone estudiar la ampliación del art. 172 ter CP para cubrir mejor las conductas de suplantación de personalidad (medida n. ${ }^{\circ}$ 111), dejar de considerar como delitos leves las injurias y calumnias a través de redes sociales en el ámbito de la violencia de género (medida $n .^{\circ} 112$ ), así como excluir la relevancia del consentimiento de la víctima en el quebrantamiento de condena (medida $n .^{\circ} 118$ ).

b) La n. ${ }^{\circ} 106$ reza lo siguiente: "suprimir la atenuante de confesión en los delitos de violencia de género, cuando las circunstancias de los hechos permitan atribuir fehacientemente su autoría, siempre que se respeten los estándares de constitucionalidad en relación con el principio de igualdad". Esta propuesta coincide textualmente con la n. ${ }^{\circ} 88$ contenida en el Informe del Congreso, aunque también guarda relación con la n. ${ }^{\circ} 240$ del Informe de la Ponencia del Senado, si bien ésta, más cautelosa, reservaba la posible supresión a delitos con resultado de muerte, fueran o no de género, y que, al menos, la rebaja no fuera automática por el mero hecho de declarar la culpabilidad. Pues bien, prever la inaplicación de una circunstancia atenuante común inauguraría una excepción en la relativa discrecionalidad del juez para apreciar circunstancias atenuantes, ya que debe hacerlo de acuerdo a un determinado fundamento material que explique la atenuación y los correlativos requisitos legales, aunque se permite la analogía y por ello su campo de aplicación es abierto, lo que choca frontalmente con su supresión para estos delitos. La propuesta carece de precedentes, pero también de justificación, y ello al margen de los estándares constitucionales con relación al principio de igualdad, por cuanto respecto de una misma conducta el hombre se vería privado de una atenuación que sí se reconocería para la mujer al obrar de modo semejante. Por un lado, no se comprende que se pueda suprimir una atenuante respecto de todos delitos de violencia de

ad) violencia sexual, incluida la violación (art. 36, “cometer intencionadamente la penetración vaginal, anal u oral no consentida, con carácter sexual, del cuerpo de otra persona con cualquier parte del cuerpo o con un objeto, los demás actos de carácter sexual no consentidos, así como el hecho de obligar a otra persona a prestarse a actos de carácter sexual no consentidos con un tercero", conductas que pueden subsumirse en su mayor parte dentro de las figuras delictivas comunes del Título VIII del CP, aunque no impliquen en todos los casos la existencia del concepto jurídico-penal de violencia, pudiendo tratarse de abusos no violentos);

ae) matrimonios forzosos (art. 37, "hecho intencionado de obligar a un adulto o a un menor a contraer matrimonio o de engañarle para que llevarlo al territorio de una Parte o de un Estado distinto a aquel en el que reside con la intención de obligarlo a contraer matrimonio", comportamientos que se encuentran reconocidos como delitos comunes en el art. 172 bis CP desde 2015);

af) acoso sexual (art. 40, “comportamiento no deseado, verbal, no verbal o físico, que tenga por objeto o resultado violar la dignidad de una persona, en particular cuando dicho comportamiento cree un ambiente intimidatorio, hostil, degradante, humillante u ofensivo", el cual puede ser castigado con sanciones penales u otro tipo de sanciones legales, es decir, que puede ser delito o constituir otra clase de infracción del ordenamiento jurídico; tales hechos son contemplados en nuestra legislación como delito común [en el art. $184 \mathrm{CP}$ ], como infracción laboral en las empresas [art. 8.13 de la Ley sobre infracciones y sanciones en el orden social] o como falta disciplinaria en el ámbito de la Administración [art. 95.2.b) de la Ley del Estatuto Básico del Empleado Público]).

Sin embargo, la medida n. ${ }^{\circ} 104$ aclara que la atención y recuperación, con reconocimiento de derechos específicos de las mujeres víctimas de cualquier acto de violencia contemplado en el Convenio de Estambul, y no previsto por la LO 1/2004, se regirá por las leyes integrales y específicas que se dicten al efecto de adecuar la necesidad de intervención y de protección a cada tipo de violencia. Entre tanto esto no se produzca se prevé que reciban un tratamiento preventivo y estadístico, pero "la respuesta penal en estos casos se regirá por lo dispuesto en el Código penal y las leyes penales especiales”. Por lo tanto, a todos esos delitos del convenio, para ser considerados desde la perspectiva de género, les podrá ser de aplicación en su caso la agravante de género, aunque particular y destacadamente en los delitos sexuales y de mutilación genital femenina, como se verá más adelante. 
género (recordemos que la mayoría aluden a conductas leves, puntuales y ocasionales), y no de otros que son mucho más graves, como terrorismo, asesinatos, etc. Por otro lado, la inaplicación de la atenuante -más que su supresión- "cuando los hechos permitan atribuir fehacientemente la autoría del delito" tendría que generalizarse para el resto de delitos comunes (tanto si la víctima es mujer como si es hombre) si se estima que no se justifica la atenuación de la pena en la medida en que deja de tener fundamento una disminución de la pena basada no solo en las menores exigencias de prevención especial, sino sobre todo en la necesidad de favorecer el funcionamiento de la Administración de Justicia, coadyuvando a la pronta resolución de las causas. ${ }^{87}$ Precisamente por estar fundada ya no en un elemento subjetivo de arrepentimiento, sino en la utilidad de la confesión, es cierto que pueden existir evidencias incuestionables que resten valor a la confesión negando un efecto atenuante a la aceptación de la evidencia. Y si bien hay que huir de automatismos en la aplicación de la atenuante ajenos a criterios teleológicos, ${ }^{88}$ sin embargo, como señala la STS $155 / 2004$, de 9 febrero, "la aceptación de unos hechos que, de otra forma, precisarían de una investigación, es una conducta que facilita la labor de la justicia y que, de otro lado, revela una menor necesidad de pena al suponer una aceptación del mal realizado y una colaboración en el retorno a la situación de vigencia efectiva del ordenamiento jurídico", por lo que si ésta se produjo antes de conocer que el procedimiento judicial se dirigía contra el autor, se dan todos los requisitos legales para apreciar la circunstancia, aunque otra cosa será cuál deba ser entonces el efecto atenuante de la circunstancia, que puede limitarse al mínimo posible (en este sentido la SAP de Valencia, sec. 1, 455/2019, de 21 de octubre). Debe tenerse en cuenta, además, que está generalmente admitida la circunstancia atenuante análoga con relación a la confesión cuando no concurren todos sus requisitos, particularmente el cronológico, aplicando el TS la atenuante analógica si el culpable colabora con su confesión de manera activa y eficiente con los fines de la Justicia (STS 692/2012, de 25 septiembre).

c) La n. ${ }^{\circ} 107$ prevé "suprimir la atenuante de reparación del daño en los casos de violencia de género". La propuesta de supresión, a diferencia de la anterior, adolece de cualquier mínimo razonamiento y es tan objetable como aquélla. Aunque la reparación del daño pudiera mantener algunos efectos al margen de la atenuación de la pena (por ejemplo, para la suspensión de la pena privativa de libertad), no se explica ni justifica la posible eliminación de esta circunstancia atenuante con relación a los delitos de violencia de género. ${ }^{89}$ Con semejante ausencia de motivación podría proponerse la supresión de toda circunstancia atenuante en estos delitos, o al menos de aquellas que dependan del agresor, como la grave adicción o el arrebato u obcecación. Pero cabe preguntarse qué delitos tan graves son éstos que estarían sustraídos al régimen general de las atenuantes: ¿solo los tipos de violencia de género, que en

${ }^{87}$ Garro Carrera/Asúa Batarrita, Atenuantes de reparación y confesión, 2008, pp. 193 ss., quienes añaden que la incidencia mayor o menor sobre la pena "debería determinarse analizando el nivel de compensación que el comportamiento postdelictivo aportó respecto de la necesidad de declarar la culpabilidad del sujeto e imponerle una sanción que revoque la conmoción creada por el delito”.

${ }^{88}$ Garro Carrera/Asúa Batarrita, Atenuantes de reparación y confesión, 2008, p. 195.

${ }^{89} \mathrm{La}$ frecuencia en la aplicación de esta circunstancia y de la anteriormente mencionada en la letra b) en los delitos de violencia de género, como argumento para llegar a plantearse su supresión, es dudosa. En el Estudio sobre la aplicación de la Ley integral contra la violencia de género por las Audiencias Provinciales (realizado por el CGPJ, publicado en marzo de 2016 y accesible desde la web del Poder Judicial: www.poderjudicial.es) se indica que “confesión y reparación del daño aparecen como circunstancias atenuantes en cinco sentencias cada una (1,33\% del total de sentencias condenatorias en cada caso), lo que supone una prevalencia inversa a la observada en las causas por delitos contra la vida consumados, en las que es moneda corriente la confesión y harto excepcional la reparación; divergencias que se explican fácilmente como consecuencia de la distinta gravedad de los delitos” (p. 213). 
general representan conductas leves y ocasionales, o también cualquier delito grave, menos grave o leve, en el que se aprecie la concurrencia de la agravante de haber obrado por razones de género? Por el contrario, y esto sí resulta llamativo, el Pacto de Estado contra la violencia de género no efectúa mención alguna al rechazo de que la cultura, la costumbre, la religión, la tradición o el supuesto "honor" puedan servir para justificar (excluyendo la pena o atenuándola) cualquiera de los actos de violencia incluidos en el ámbito de aplicación del Convenio de Estambul (como se previene expresamente en su art. 42).

d) La n. ${ }^{\circ} 108$ indica "generalizar la aplicación de la circunstancia agravante del artículo 22.4 del Código Penal para los casos de mutilación genital femenina". Entendiendo que dicha propuesta está referida a la agravante de género, resulta controvertido cómo se puede "generalizar" la aplicación de tal circunstancia, pues la misma tendrá que ser aplicada única y exclusivamente cuando concurran sus requisitos (objetivos y subjetivos), tanto en el delito de mutilación genital femenina, como en todos aquellos, estén o no especialmente previstos en el Convenio de Estambul, en los que proceda aplicar dicha circunstancia. En principio ello será posible en la medida en que nuestro CP establece un delito de mutilación genital genérico del que puede ser autor y víctima tanto el hombre como la mujer (art. 149.2), por lo que la circunstancia de género no es inherente al delito (incluso sería aplicable a un sujeto activo mujer que realizara la conducta por razones de género).

e) La n. ${ }^{\circ} 110$ relativa a "recomendar la aplicación de la circunstancia $4^{a}$ del art. 22 del Código penal, en todos los casos en los que resulte probado el elemento subjetivo de motivos machistas o discriminatorios hacia la mujer, o por razones de género, en los casos de agresión y abuso sexual de los artículos 178 a 183 bis del Código Penal" se conecta claramente con la propuesta anteriormente reseñada, aunque difieren en el verbo con que se explicitan una y otra, esto es, en aquel caso "generalizar" y en este "recomendar". Ni lo uno ni lo otro procede como materia legislativa, en tanto en cuanto la vigencia del Convenio de Estambul, de la propia circunstancia agravante de "razones de género" y de la jurisprudencia sobre la misma, hacen innecesario e inane cualquier otra medida de tipo legislativo, correspondiendo solo en sede judicial aplicar o no la agravante, al margen de recomendaciones o pretendidas generalizaciones. Pero si en este caso se recomienda también que resulte probado el elemento subjetivo de motivos machistas o discriminatorios hacia la mujer o por razones de género es porque, quizás, en las violencias sexuales el contexto discriminatorio hacia la mujer resulta consustancial a esta clase de comportamientos tan subculturalmente condicionados, pero no lo es en cambio la motivación sexista del autor, que habría que probarla caso por caso.

f) En el n. ${ }^{\circ} 113$ se alude a "incluir en la redacción del artículo 184 del Código Penal, una circunstancia específica en los delitos de acoso sexual, que debería contemplar el móvil de actuar por razones de género, atentando gravemente contra la dignidad de la mujer". A diferencia de los dos casos anteriores en los que se parte de la aplicación de una circunstancia agravante genérica y común a todos los delitos, respecto del delito de acoso sexual se propone insertar en el tipo una circunstancia agravante específica que no se acierta a entender de entrada, porque al margen de exigir un determinado móvil del autor, se vincula a un atentado grave contra la dignidad de la mujer. Dicho concepto jurídico indeterminado dificultaría la apreciación de la circunstancia específica, dando lugar a preguntarse si habría que apreciar la circunstancia genérica cuando dicho atentado contra la dignidad de la mujer no fuera calificado de grave. Por ello lo lógico sería mantener una posición legislativa coherente y sistemática con todos los delitos que son calificados como violencia de género o, más ampliamente, de violencia contra la mujer, en la medida en este último caso en el que sean compatibles con la agravante de género: 
o bien incluir una agravante específica en todos, o bien dejar abierta la apreciación judicial de las agravantes genéricas cuando se pruebe su concurrencia.

g) En el n. ${ }^{\circ} 128$ se menciona la "modificación del Art. 22.8 del Código Penal para considerar reincidencia cuando el mismo hombre cometiera distintos delitos contra la misma mujer, en consonancia con el Convenio de Estambul, abriendo la posibilidad de incluir reincidencia si el mismo hombre comete distintos delitos de esta naturaleza contra distintas mujeres". El Convenio de Estambul no se pronuncia sobre una definición o concepto de reincidencia que comprenda el supuesto de que un hombre cometa distintos delitos contra la misma mujer o diversos delitos de género contra distintas mujeres. Contempla únicamente en el art. 46 como circunstancia agravante, siempre que no sea de por sí elemento constitutivo del delito, "que el delito, o los delitos conexos, se hayan cometido de forma reiterada”. Respecto de la propuesta de confusa redacción, la ampliación de la agravante de reincidencia, más allá de la reincidencia específica prevista en el Código penal (delito comprendido en el mismo Título del Código penal, siempre que sea de la misma naturaleza), cuando se trate de la misma mujer o, incluso, de distintas mujeres no se justifica desde la perspectiva de género, pues cometer varios delitos contra una misma mujer no significa automáticamente que estén presentes la razones de género que deberían subyacer a la ampliación de la circunstancia agravante. Por tanto, de estimarse necesaria una ampliación de la agravante de reincidencia habría de serlo porque un mismo hombre cometiera distintos delitos contra la misma mujer o distintas mujeres "por razones de género".

\section{Epílogo}

En suma, nos encontramos ante un panorama normativo muy complejo, confuso e inacabado. Falta también un estudio serio y una justificación convincente para las modificaciones penales pendientes en el plano legislativo, sobre todo las relativas a suprimir atenuantes y generalizar agravantes. Asimismo, el consenso que se pretendía recuperar respecto de la LO 1/2004 para avanzar hacia nuevos pactos, dirigidos a combatir la violencia contra la mujer por razones de género mediante instrumentos penales, hoy por hoy ya parece inalcanzable en el nuevo escenario político. Por otro lado, las posiciones antagónicas y las incongruencias sobre el fundamento y ámbito de la agravante de género y de los propios tipos de violencia de género en nuestra jurisprudencia no contribuyen a mejorar las expectativas de lograr una regulación jurídica de los delitos con perspectiva de género que sea armónica, convincente y conveniente. La propia coexistencia de la agravante de género con los tipos de violencia de género suscita serios inconvenientes. Seguramente todo ello sea debido a que la tendencia expansiva del Derecho Penal en nuestro país en materia de violencia de género y su discurso simbólico no parecen tener ni conocer límites, ${ }^{90} \mathrm{y}$, sin embargo, es necesario reivindicarlos una y otra vez para denunciar la posible -por no decir acreditada, constante y creciente- vulneración de sus principios fundamentales.

\footnotetext{
${ }^{90}$ Como señala Ruiz Miguel, Jueces para la Democracia, (55), 2006, p. 44, "el uso simbólico del Derecho Penal, que seguramente le es consustancial, puede ser positivo, al menos cuando no se abusa de él" (cursivas añadidas).
} 


\section{Bibliografía}

ACALE SÁNCHEZ (2018), «La interpretación judicial del derecho penal desde la perspectiva holística del género», Jueces para la Democracia, (92), pp. 26-43.

(2018), «Derecho Penal y violencia de género», en MARTín SÁNCHEZ (dir.), Estudio Integral de la Violencia de Género: un análisis teórico-práctico desde el Derecho y las Ciencias Sociales, Valencia, pp. 403-441.

(2010), «La perspectiva de género en el Derecho Penal Español», en FARALDo CABANA (dir.), Género y sistema penal: una perspectiva internacional, Granada, pp. 3-30.

(2009), «Análisis del Código penal en materia de violencia de género contra las mujeres desde una perspectiva transversal», Revista electrónica del Departamento de Derecho de la Universidad de La Rioja - REDUR, (7), pp. 37-73.

(2006), La discriminación hacia la mujer por razón de género en el Código penal, Madrid.

ALASTUEY DOBÓN/ESCUCHURI AISA (2015), «La violencia de género y la violencia doméstica en el contexto legislativo español», Revista de Derecho Penal, (23), pp. 37-78.

Alonso Álamo (2019), «El delito de feminicidio. Razones de género y técnica legislativa», en Monge FERNÁNDEZ (dir.), Mujer y Derecho Penal. ¿Necesidad de una reforma desde una perspectiva de género?, Barcelona, p. 91-129.

(2008), «Protección penal de la igualdad y Derecho penal de género», Cuadernos de Política Criminal, (95), pp. 19-52.

(2002), «La circunstancia agravante de discriminación», en DíEz RIPOLLÉs et al. (coords.), La ciencia del Derecho Penal ante el nuevo siglo. Libro homenaje al Profesor Doctor Don José Cerezo Mir, Madrid, pp. 533-542.

AÑón RoIG (2012), «Violencia de género: un concepto jurídico intricado», en MARTínEZ GARCÍA (dir.), La prevención y erradicación de la violencia de género: un estudio multidisciplinar y forense, Madrid, pp. 31-53.

Boldova PASAMAR/RUEDA MARTín (2006), «Consideraciones político-criminales en torno a los delitos de violencia de género», en BOLDOVA PASAMAR/RUEDA MARTín (coords.), La reforma penal en torno a la violencia doméstica y de género, Barcelona, pp. 13-34.

Bolea Bardón (2007), «En los límites del Derecho Penal frente a la violencia doméstica y de género», Revista Electrónica de Ciencia Penal y Criminología, (9-2), pp. 1-26.

BORJA JIMÉNEZ (2015), «La circunstancia agravante de discriminación del art. 22.4 ${ }^{\mathrm{a}}$, en GoNZÁLEZ CusSAC (dir.), Comentarios a la reforma del Código penal de 2015, $2^{\mathrm{a}}$ ed., Valencia. 
CADENA SERRANo (2019), «Aplicación de la circunstancia atenuante de actuar por razones de género», La Ley Digital, La Ley 8669/2019.

Carreras Presencio (2019), Concepto jurídico de violencia de género, Madrid.

COMAS D’ARgEMir CendRA (2006), «La Ley Integral contra la Violencia de Género. Nuevas vías de solución», en BOLDOVA PASAMAR/RUEDA MARTín (coords.), La reforma penal en torno a la violencia doméstica y de género, Barcelona, pp. 35-56.

CONGRESO DE LOS DiPUTADOS (2017): Informe de la Subcomisión creada en el seno de la Comisión de Igualdad para un Pacto de Estado en materia de violencia de género; https://violenciagenero.igualdad.gob.es/eu/pactoEstado/docs/PactodeEstado_Congreso.pdf

CONSEjo General del Poder Judicial (2016), Estudio sobre la aplicación de la Ley integral contra la violencia de género por las Audiencias Provinciales, 2016; http://www.poderjudicial.es/cgpj/es/Temas/Violencia-domestica-y-de-genero/Grupos-deexpertos/Estudio-sobre-la-aplicacion-de-la-Ley-integral-contra-la-violencia-de-genero-porlas-Audiencias-Provinciales--Marzo-2016-

COUNCIL OF EUROPE (2011), Explanatory Report to the Council of Europe Convention on preventing and combating violence against women and domestic violence», Council of EuropeTreaty Series, n. 210.

DíEZ RIPOLLÉs (2016), Derecho Penal Español, Parte General, 4ª ed., Valencia.

Dopico Gómez-Aller (2019), «Motivos racistas o similares», en Memento Práctico Penal Francis Lefebvre, Madrid.

GARCÍA ARÁN (2009), «Injusto individual e injusto social en la violencia machista. (A propósito de la STC 59/2008 sobre el maltrato masculino a la mujer pareja)», en CARBONELL MATEU et al. (coords.), Constitución, derechos fundamentales y sistema penal. Semblanzas y estudios con motivo del setenta aniversario del Profesor Tomás Salvador Vives Antón, t. I, Valencia, pp. 649-670.

GaRro CARRERA/Asúa BAtarrita (2008), Atenuantes de reparación y confesión. Equívocos de la orientación utilitaria (A propósito de una controvertida sentencia del Juzgado de lo Penal $n .^{\circ} 8$ de Sevilla), Valencia.

Goyena Huerta (2015), «Artículo 22», en Gómez Tomillo (dir.), Comentarios al Código penal, t. I, Aranzadi.

JERICó OJER (2019), «Perspectiva de género, violencia sexual y Derecho Penal», en Monge FERNÁNDEZ (dir.), Mujer y Derecho Penal. ¿Necesidad de una reforma desde una perspectiva de género?, Barcelona, pp. 285-337.

LARRAURI PiJOAN, (2018), Criminología crítica y violencia de género, $2^{\mathrm{a}}$ ed., Madrid.

(1), 2009.

(2009), «Igualdad y violencia de género. Comentario a la STC 59/2008», InDret 
LAURENZO COPELlo (2015), «¿Hacen falta figuras de género específicas para proteger a las mujeres?», Estudios Penales y Criminológicos, (35), pp. 783-830.

(2005), «La violencia de género en la Ley Integral. Valoración políticocriminal», Revista Electrónica de Ciencia Penal y Criminología, (07-08), pp. 1-23.

(1996), «La discriminación en el Código penal de 1995», Estudios Penales y Criminológicos, (19), pp. 219-288.

LERAY/MONSALVE (2017), «Un crime de féminicide en France? A propos de l'article 171 de la loi relative à l'égalité et à la citoyenneté», en Revue du Centre de recherches et d'études sur les droits fondamentaux, Actualités Droits-Libertés, (http://journals.openedition.org/revdh/2967).

Magro Servet (2019), Prólogo al Memento experto Violencia Machista, La Ley Digital, Francis Lefebvre.

(2013), La carga de la prueba de la intención de dominación o machismo en la violencia de género», La ley penal, (104), p. 11.

MAQUEDA ABREU (2017), «¿Necesitan un móvil discriminatorio las agravantes de sexo/género del art. 22.4 CP?», en Estudios de Derecho penal, Homenaje al profesor Santiago Mir Puig, Buenos Aires, p. 703-714.

(2016), «El hábito de legislar sin ton ni son. Una lectura feminista de la reforma penal de 2015», Cuadernos de Política Criminal, (118), pp. 5-42.

(2006), «La violencia contra las mujeres: una revisión crítica de la Ley Integral», Revista Penal, (18), pp. 176-187.

MARÍN DE EsPiNOSA CEBALLOS (2018), «La agravante genérica de discriminación por razones de género (art. 22.4 CP)», Revista Electrónica de Ciencia Penal y Criminología, (20-27).

Mir PUIG (2015), Derecho Penal, Parte General, 10ª ed., Barcelona.

MOLINA FERNÁNDEZ (2009), «Desigualdades penales y violencia de género», Anuario de la Facultad de Derecho de la Universidad Autónoma de Madrid, (13), pp. 57-88.

Muñoz Conde/García Arán (2019), Derecho Penal, Parte General, $10^{a}$ ed., Valencia.

Pacto de Estado Contra la Violencia de GÉnero (2019), Documento refundido de medidas del Pacto de Estado en materia de violencia de género. Congreso + Senado (13 de mayo de 2019); http://www.violenciagenero.igualdad.mpr.gob.es/pactoEstado/docs/Documento_Refundido_PE VG_2.pdf

PÉREZ MANZANO (2016), «Algunas claves del tratamiento penal de la violencia de género: acción y reacción», Revista Jurídica Universidad Autónoma de Madrid, (34), pp. 17-65. 
QUERALT JIMÉNEZ (2006), «La última respuesta penal a la violencia de género», La Ley, (1), pp. 1423-1436.

Rebollo VARgas (2015), «La agravante de discriminación por razón de sexo y su fundamento (art. 22.4 del Código Penal)», Revista General de Derecho Penal, (23).

RoIG TORRES (2012), «La delimitación de la "violencia de género": un concepto espinoso», Estudios Penales y Criminológicos, (32), pp. 247-312.

RUEDA MARTíN (2019), «Cometer el delito por discriminación referente al sexo de la víctima y/o razones de género como circunstancia agravante genérica», Revista Electrónica de Ciencia Penal y Criminología, (21-04).

RuIZ Miguel (2006), «La ley contra la violencia de género y la discriminación positiva», Jueces para la Democracia, (55), pp. 35-47.

SAN Millán FeRnÁNDEZ (2019), «Estudio dogmático y jurisprudencial sobre la agravante de discriminación por razones de género», Estudios Penales y Criminológicos, (39), pp. 303-351.

SANZ Mulas (2019), Violencia de género y Pacto de Estado, La huida hacia delante de una norma agotada (LO 1/2004), Valencia.

(2019), «El primer paso fallido del Real Decreto-Ley 9/2018, de 3 de agosto, de medidas urgentes para el Pacto de Estado contra la violencia de género», Revista Penal, (43), pp. 137-155.

Senado (2017), Informe de la Ponencia de Estudio para la elaboración de estrategias contra la violencia de género;

https://violenciagenero.igualdad.gob.es/eu/pactoEstado/docs/PactodeEstado_Senado.pdf

SERRANO GONZÁleZ DE MURILlo (2019), «Violencia machista y circunstancia mixta de parentesco», Revista Penal, (44), pp. 199-213.

TAMARIT Sumalla (2018), «Violencia de género: una política criminal sin base empírica», $E l$ cronista del Estado Democrático y Social de Derecho, (77), pp. 22-33.

Villacampa Estiarte (2018), Política criminal española en materia de violencia de género. Valoración crítica, Valencia.

(2018), «Pacto de estado en materia de violencia de género: ¿más de lo mismo?», Revista Electrónica de Ciencia Penal y Criminología, (20-04). 